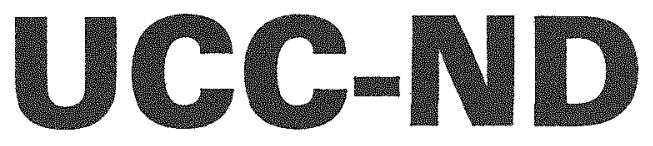

\title{
NUGLEAR DIVISION
}

\section{UNION \\ CARBIDE}

\section{THERMODYNAMIC DATA FOR URANIUM FLUORIDES}

J. M. Leitnaker

Materials and Chemistry Technology

Process Support

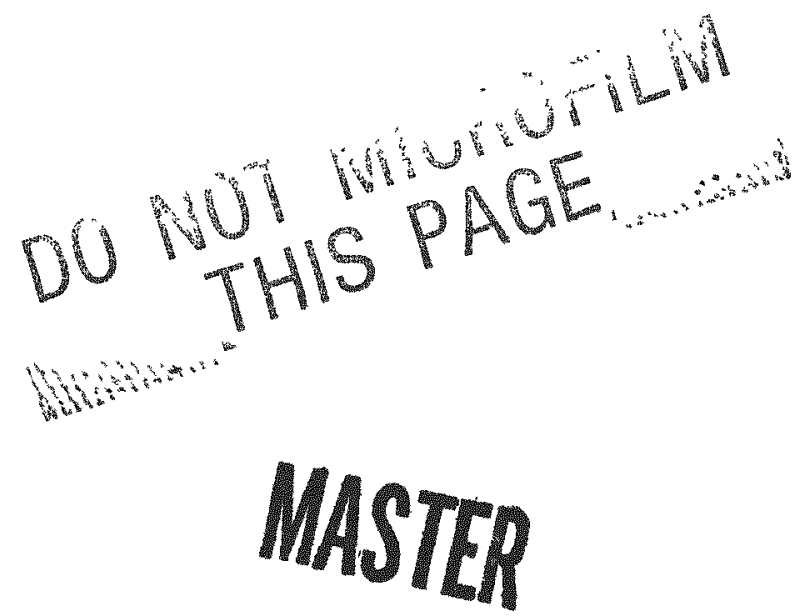

MARCH 1983
OPERATED BY

UNION CABBIOE CORPOBATION FOR THE UNIED STATES DEPARTMENT OF ENEREY 


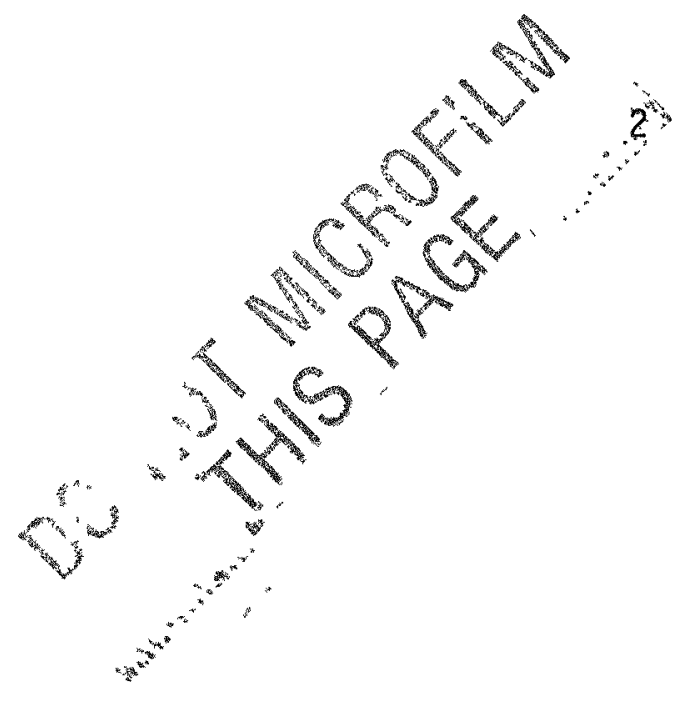

\section{DISCLAIMER}

This report was prepared as an account of work sponsored by an agency of the United States Government. Nether the United States Government nor any agency thereof, nor any of their employees, makes any warranty, express or implied, or assumes any legal liability or responsibility for the accuracy, completeness, or usefulness of any information, apparatus, product, or process disclosed, or represents that its use would not infringe privately owned rights. Reference herein to any specific commercial product, process, or service by trade name, trademark, manufacturer, or otherwise, does not necessarily constitute or imply its endorsement, recommendation, or favoring by the United States Government or any agency thereof. The views and opinions of authors expressed herein do not necessarily state or reflect those of the United States Government or any agency thereof. 


\section{DISCLAIMER}

This report was prepared as an account of work sponsored by an agency of the United States Government. Neither the United States Government nor any agency Thereof, nor any of their employees, makes any warranty, express or implied, or assumes any legal liability or responsibility for the accuracy, completeness, or usefulness of any information, apparatus, product, or process disclosed, or represents that its use would not infringe privately owned rights. Reference herein to any specific commercial product, process, or service by trade name, trademark, manufacturer, or otherwise does not necessarily constitute or imply its endorsement, recommendation, or favoring by the United States Government or any agency thereof. The views and opinions of authors expressed herein do not necessarily state or reflect those of the United States Government or any agency thereof. 


\section{DISCLAIMER}

Portions of this document may be illegible in electronic image products. Images are produced from the best available original document. 
Date of Issue: January 25, 1983

Report Number: K/PS-352

THERMODYNAMIC DATA FOR URANIUM FLUORIDES

$R / P S-352$

DE83 011049

\author{
J. M. Leitnaker \\ Materials and Chemistry Technology \\ Process Support \\ Union Carbide Corporation, Nuclear Division \\ Oak Ridge Gaseous Diffusion Plant \\ Oak Ridge, Tennessee \\ Prepared for the U.S. Department of Energy \\ Under U.S. Government Contract W-7405 eng 26
}

\title{
DISCI.AMER
}

This report was prepared as an account of work sponsored by an agency of the United States Government. Neither the United States Government nor any agency thereof, nor any of their employees, makes any warranty, express or implied, or assumes any legal liability or responsibility for the accuracy, completeness, or usefulness of any information, apparatus, product, or process disclosed, or represents that its use would not infringe privately owned rights. Reference herein to any specific commercial product, process, or service by trade name, trademark, manufacturer, or otherwise does not necessarily constitute or imply its endorsement, recommendation, or favoring by the United States Govermment or any agency thereof. The views and opinions of authors expressed herein do not necessarily state or reflect those of the United States Government or any agency thereof. 


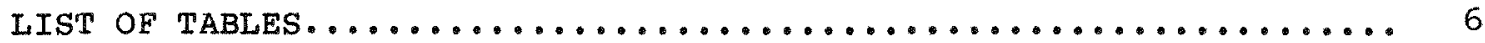

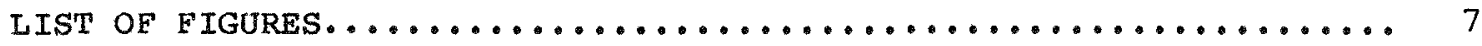

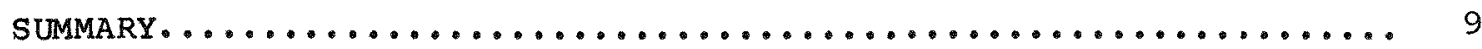

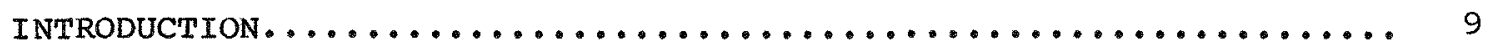

THERMODYNAMIC EUNCTIONS OF URANIUM FLUORIDES . . . . . . . . . . . . .

TRANSPORT OF URANIUM PENTAFLUORIDE. .......................... 24

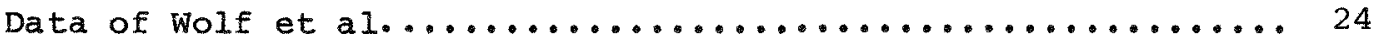

Enhanced Transport by Uranium Hexafluoride................ 24

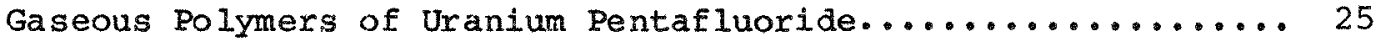

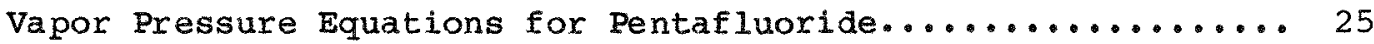

ENTHALPIES OF FORMATION OF URANIUM FLUORIDES. . . . . . . . . . . . . 28

The Heat of Formation of $\mathrm{UF}_{6}$ and $\mathrm{UF}_{4} \ldots \ldots \ldots \ldots \ldots \ldots \ldots \ldots$

Recalculation of Thermodynamic Data Erom Equilibrium

Pressures of $\mathrm{UF}_{6}$ over Intermediate Fluorides.............. 28

VAPORIZATION BEHAVIOR OF THE URANIUM-ELUORIDE SYSTEM............ 34

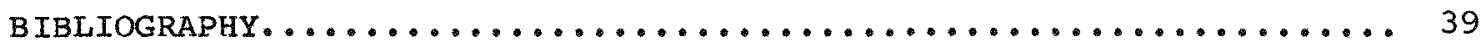

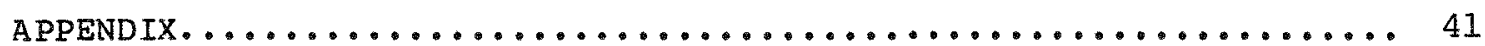


TABLE 1. THERMODYNAMIC FUNCTIONS FOR CONDENSED URANIUM.......... 14

TABLE 2. THERMODYNAMIC FUNCIIONS FOR UF 4 (SOLID)........... 15

TABLE 3. THERMODYNAMIC EUNCTIONS FOR UF 4.25 (SOLID).......... 16

TABLE 4. THERMODYNAMIC EUNCTIONS FOR UF 4.5 (SOLID) .......... 17

TABLE 5. THERMODYNAMIC FUNCTIONS FOR UF (ALPHA)............ 18

TABLE 6. THERMODYNAMIC FUNCTIONS FOR UF 6 (SOLID AND LIQUID)..... 19

TABLE 7. THERMODYNAMIC FUNCTIONS FOR UF 5 (GAS) $\ldots \ldots \ldots \ldots \ldots \ldots \ldots$

TABLE 8. THERMODYNAMIC FUNCTIONS FOR $\mathrm{U}_{2} \mathrm{~F}_{10}$ (GAS)........... 21

TABLE 9. THERMODYNAMIC EUNCTIONS FOR UF 6 (GAS) $\ldots \ldots \ldots \ldots \ldots \ldots \ldots 22$

TABLE 10. THERMODYNAMTC FUNCTIONS FOR $F_{2}$ (GAS)............ 23

TABLE 11. RECALCULATED ENTHALPIES AND ENTROPIES OE DECOMPOSITION

OF INTERMEDIATE FLUORIDES................. 32

TABLE 12. ENTHALPIES OF FORMATION OF INTERMEDIATE URANIUM FLUORIDES 33

TABLE 13. THERMODYNAMIC QUANTITIES FOR URANIUM-FLUORINE COMPOUNDS.. 36

TABLE 14. EQUILIBRIUM PRESSURES OVER SOLID PHASES IN THE U-F SYSTEM

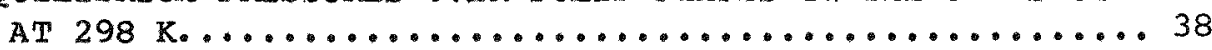


LIST OF FIGURES

Page

FIGURE 1. PRESSURE - TEMPERATURE RELATIONSHIPS

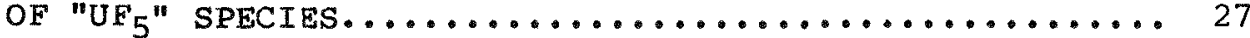

FIGURE 2. PRESSURE-COMPOSITION RELATIONSHIPS IN THE

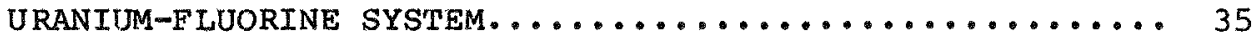


8 


\section{SUMMARY}

Self-consistent thermodynamic data have been tabulated for uranium fluorides between $\mathrm{UF}_{4}$ and $\mathrm{UF}_{6}$, including $\mathrm{UF}_{4}$ (solid and gas), $\mathrm{U}_{4} \mathrm{~F}_{17}$ (solid), $\mathrm{U}_{2} \mathrm{~F}_{9}$ (solid), $\mathrm{UF}_{5}$ (solid and gas), $\mathrm{U}_{2} \mathrm{~F}_{10}$ (gas), and $\mathrm{UF}_{6}$ (solid, liquid, and gas). Included are thermal functions -- the heat capacity, enthalpy, and free energy function, heats of formation, and vaporization behavior.

\section{INTRODUCTION}

The purpose of this document is to tabulate self-consistent thermodynamic data for uranium fluorides. In addition to selecting data from the literature, a number of enthalpies of formation as well as entropies have been derived, notably of the intermediate fluorides and the $\mathrm{UF}_{5}$ and $\mathrm{U}_{2} \mathrm{~F}_{10}$ gases. This tabulation has the advantage that a consistent set of thermal functions and heats of formation data are collected in one document. Much of the thermal function data for the intermediate fluorides are estimated, but, when used with the calculated enthalpies of formation for the compounds, they yield values consistent with the known thermodynamic data.

Consistency is an important consideration in the choice of thermodynamic data. For example, we have used the value of 45.3 e.u.* for the entropy of $\alpha-U_{5}$. A recent publication by the National Bureau of standards 1 uses the value of $47.7 \mathrm{e} . \mathrm{u}$. For this same quantity which results in a difference of 2.4 e.u. for the entropy of vaporization. For UF 5 pressure calculations at $1400 \mathrm{~K}$, a difference of a factor of 3.3 results, which would raise the calculated pressure of UF $_{5}$ from less than an atmosphere to nearly three atmospheres-not a trivial difference.

\section{THERMODYNAMIC FUNCTIONS OF URANIUM FLUORIDES}

In this section the thermodynamic functions $C_{p} / R,\left(H^{\circ} T^{-H^{\circ}} 298\right) / R, S^{\circ}{ }_{T} / R$, and $\left(\mathrm{G}^{\circ} \mathrm{T}^{-\mathrm{H}^{\circ}}{ }_{298}\right) / \mathrm{RT}$ are tabulated for those uranium fluorides for which we can either obtain data or can reasonably estimate the quantities involved. We choose to tabulate dimensionless quantities, except for $\left(H^{\circ} \mathrm{T}-\mathrm{H}^{\circ} 298\right) / \mathrm{R}$, for which the unit is Kelvin. The functions are tabulated in Tables 1 through 10 at the end of this section.

Thermal functions for the elements, condensed uranium ${ }^{2}$ and gaseous fluorine, ${ }^{3}$ are reddily available and not in doubt. They have been tabulated here for completeness and convenience of a user of the tables. While thermal functions of $\mathrm{UF}_{6}$ in both the condensed and the gaseous phases are well established, they have not been conveniently tabulated. Brickwedde et al. 4 reported the heat capacity of the condensed hexafluoride from 14 to $350 \mathrm{~K}$. Weinstock et al.5 thoroughly reevaluated the vapor pressure data of $\mathrm{UF}_{6}$, as well as spectroscopic constants of the gas and its equation of state. The agreement among those sets of data bearing

\footnotetext{
* See Appendix for explanation of terms.
} 
on the thermodynamic properties of $\mathrm{UF}_{6}$ is excellent. It is interesting that in order to bring the structural information on gaseous $\mathrm{UF}_{6}$ into agreement with thermodynamic data the theory on electron diffraction had to be modified. 6 The interesting sequence of events is not directly recorded but can be appreciated by following the references back from weinstock et al. 5

For solid $\mathrm{UF}_{4}$ the thermal data are in reasonable accord. The low temperature data have been carefully obtained by Burns et al. 7 Dworkin's 8 high temperature measurements reaffirm those of King and Christensen 9 . Although there are differences between the two measurements of about 18 in the measured heat content, the differences are probably within the inherent errors in this type of preparation and measurement.

The vaporization behavior of $\mathrm{UF}_{4}$ has recently been reexamined, 10 and i.t is clear that the data are in accord with vaporization to the $\mathrm{UF}_{4}$ monomer. There is general agreement among the various experimenters on the vapor pressure over the solid. However, the derived entropy for the gas did not agree with the entropy calculated for a tetrahedral molecule. Lau and Hildenbrand ${ }^{11}$ have recently pointed out that essentially all of the discrepancy can be removed by using a less symmetrical model for $\mathrm{UF}_{4}$ $\left(\mathrm{C}_{2 \mathrm{v}}\right)$ and a reestimation of vibrational and electronic energy levels. Nevertheless, the thermal functions for gaseous $\mathrm{UF}_{4}$ are not tabulated here.

Solid fluorides between $\mathrm{UF}_{4}$ and $\mathrm{UF}_{6}$ have been largely ignored by the thermochemical community. However, enough data have been obtained to allow reasonable estimates of the thermal functions to be made. The validity of the estimates can be judged by their use to correctly yield independent thermodynamic quantities by appropriate combinations. One example of such substantiation will be shown below.

The thermal functions of solids can be considered as coming from two sources, generally: a lattice contribution and an electronic contribution. In this view, the atoms are perceived to vibrate about their equilibrium lattice sites, contributing to the heat capacity as (nearly) harmonic oscillators, dependent only on a force constant and the atomic weight. This is a reasonably consistent view of solid $\mathrm{UF}_{6}$. On the other hand, an additional term must be included to explain the heat capacity of solid $\mathrm{UE}_{4}$, which may be viewed as arising from an electronic contribution by the uranium atom to the heat capacity of the solid. It is reasonable to suppose that the heat capacity of the fluorides intermediate to UF 4 and $\mathrm{UF}_{6}$ would have intermediate heat capacities and, consequently, intermediate thermal functions.

The real situation is not so simple if the fine details are considered. For example, the uranium atom in $\mathrm{UF}_{4}$ would be expected to have two electrons not used in bonding. If the electrons are unpaired, the electronic entropy expected would be $R$ ln 3 or $2.18 \mathrm{e} . u$. The entropy of $\mathrm{UF}_{4}$ at room temperature is just 2.29 e.u. greater than $\mathrm{ThF}_{4}$, which would not be expected to have any electrons unused in bonding. The electronic entropy of $\mathrm{UF}_{4}$ does not arise in a simple randomization process, however. 
A Schottky amomaly occurs in $\mathrm{UF}_{4}$ below about $20 \mathrm{~K}$, but the contribution to the entropy is only about 0.3 e.u. 12

Other fine details are troublesome. The uranium atoms are not all equivalent in $\mathrm{UF}_{4}$ as they are in $\mathrm{UF}_{6}, \mathrm{UF}_{5}$, and $\mathrm{U}_{2} \mathrm{~F}_{9}$. Even so, one can "get" to $\mathrm{U}_{4} \mathrm{~F}_{17}$ by adding $\mathrm{F}$ atoms in appropriate holes, and then to $\mathrm{U}_{2} \mathrm{~F}_{9}$ by a similar addition. In the alpha form of UF 5 all uranium atoms are bonded to six fluorine atoms; however, all the fluorine atoms are not precisely equivalent. In $\mathrm{UF}_{6}$ the uranium atoms are equivalent, as are the fluorine atoms.

The regularities suggest that a simple interpolation for the thermal functions may be satisfactory, despite the difficulties of explaining the entropy of $\mathrm{UF}_{4}$. If one averages the entropy of $\mathrm{UF}_{4}$ and $\mathrm{UF}_{6}$ at $298 \mathrm{~K}_{\text {, }}$ one obtains very nearly the entropy for $\mathrm{UF}_{5}$ reported by katz and Rabinowitch. 13 Thus, for $S^{\circ} 298 / R$ of $U F_{5}$, one estimates $(18.24+27.40) / 2$ or 22.82 , as compared to 22.65 reported for a sample of $U_{5}$ thought to be of the alpha form. The composition of the material was only about $83 \%$ $\mathrm{UF}_{5}$, the remainder being $\mathrm{UF}_{4}$ and $\mathrm{UO}_{2} \mathrm{~F}_{2}$. According to the original National Bureau of Standards report cited by Katz and Rabinowitch, 13 correction for the $\mathrm{UO}_{2} \mathrm{~F}_{2}$ was made by assuming that it had the same heat capacity as $\mathrm{UF}_{4}$. If a correction is made based on more recent data, the value of $S^{\circ} 298 / R$ derived is 22.79 rather than 22.65 . At any rate, little error results in averaging the entropies of $\mathrm{UF}_{4}$ and $\mathrm{UF}_{6}$ to get the entropy of $\mathrm{UF}_{5}$. The further interpolation to get those for $\mathrm{U}_{2} \mathrm{~F}_{9}$ and $\mathrm{U}_{4} \mathrm{~F}_{17}$ should be just as valid.

The same interpolation between $\mathrm{UF}_{4}$ and $\mathrm{UF}_{6}$ cannot be made for the heat capacity. At $298 \mathrm{~K}, \mathrm{C}_{\mathrm{p}} / \mathrm{R}$ of $\mathrm{UF}_{4}$ is $13.956, \mathrm{C}_{\mathrm{p}} / \mathrm{R} U \mathrm{UF}_{6}$ is 20.06 , and a linear interpolation yields 17.01, while the reported value for $\mathrm{UF}_{5}$ is 15.92. Since the hexafluoride melts at $64.2{ }^{\circ} \mathrm{C}$ and a pressure of 1,150 torr, one might expect to see a premelting increase in the heat capacity of $\mathrm{UF}_{6}$, accounting for the discrepancy of slightly more than 1.0 in the linear interpolation versus the measured value of $\mathrm{UF}_{5}$. It seems more appropriate to accept the reported value of the heat capacity of UF5 at $298 \mathrm{~K}$, and use this and the heat capacity of $\mathrm{UF}_{4}$ as a basis for calculating thermal functions of $\mathrm{UF}_{5}, \mathrm{U}_{2} \mathrm{~F}_{9}$, and $\mathrm{U}_{4} \mathrm{~F} 17^{\circ}$. No corrections were made for $\mathrm{UO}_{2} \mathrm{~F}_{2}$ in the $\alpha-\mathrm{UF}_{5}$ which would have increased the heat capacity by a negligible amount.

The heat capacity for $\mathrm{UF}_{4}$ from Dworkin's ${ }^{8}$ data is:

$$
C_{p} / R=14.86+1.157 \times 10^{-3} \mathrm{~T}-1.112 \times 10^{5} \mathrm{~T}^{-2}
$$

To obtain the heat capacity of $\mathrm{UF}_{5}$ as a function of temperature, each term in equation (1) is multiplied by 1.1407, and other functions are obtained by integration in the usual way. For $\mathrm{UF}_{4.5}$ the factor 1.0704 was used, and for $\mathrm{UF}_{4.25}$ the factor 1.0352 was used.

It should be emphasized that there are two forms of $\mathrm{UF}_{5}$ : alpha, stable above about $125^{\circ} \mathrm{C}$, and beta, stable at lower temperature. ${ }^{14}$ Thus, the 
low temperature heat capacity has been determined from near zero to above $298 \mathrm{~K}$ for a substance which is not stable below $\sim 370 \mathrm{~K}$. Measurement of heat capacities of unstable substances, and calculation of the third law entropy therefrom, is not unheard of. An example would be those data for diamond, a form of carbon. Perhaps somewhat more unusual is the fact that these data are not available for the stable, beta form of $\mathrm{UF}_{5}$.

While the material for which the low temperature heat capacity was measured was stated by Katz and Rabinowitch ${ }^{13}$ to be the alpha form, some doubt was cast by the source docunent which had only "presumed" the fluoride to be the alpha form. Nevertheless, it is entirely reasonable to suppose that the material was indeed the alpha form, since it was manufactured in a way recommended to give the high temperature form.

It is customary to choose the most stable condensed phase as the reference state for thermodynamic calculations at the temperature of interest, but it is not necessary to do so. In the present case it seems desirable to use $\alpha-U_{5}$ as the reference state at all temperatures. This has been the basis for estimates of heat capacities of $U_{2} \mathbb{F}_{9}\left(U_{4.5}\right)$ and $U_{4} F_{17}\left(U_{4.25}\right)$, as explained above.

Without loss of generality, one can still calculate thermodynamic quantities for $\alpha-\mathrm{UF}_{5}$ relative to the other phases in the system. There is good reason to suppose that the beta form is stable at low temperatures, below $125^{\circ} \mathrm{C}$. An entropy for $\beta-U^{-F_{5}}$ lower than that for alpha is a necessary consequence. It is also necessary to suppose, because of phase rule considerations, that the composition of the alpha and beta phases differ, if only slightly. A difference in composition has not been detected and it is assumed to be negligibly small.

If a temperature of $125^{\circ} \mathrm{C}$ is accepted as the transition point of UF, data are available to calculate the difference in entropy. O'Hare et al.15 have measured the enthalpy of solution of both forms, from which the enthalpy of transition can be derived: $7.5 \mathrm{~kJ} \mathrm{~mol}^{-1}$ at $298 \mathrm{~K}$. This value should be relatively independent of temperature, and the value of $\Delta S^{\circ}{ }_{298} / R$ is thus calculated to be 2.27, with the beta form having the lower entropy.

The entropy values at every temperature for $\beta-\mathrm{UF}_{5}$ can be computed by subtracting 2.27 from those tabulated in Table 5. Likewise, the free energy function, $-\left(G^{\circ} \mathrm{T}-\mathrm{H}^{\circ} 298\right) / \mathrm{RT}$, can be computed for $B-\mathrm{UF}_{5}$ by adaing 2.27 .

The reader may well wonder why one chooses to estimate the entropies-and, indeed, all the thermal functions--of $U_{2} \mathrm{~F}_{9}$ and $\mathrm{U}_{4} \mathrm{~F}_{17}$ from consideration of a compound which is not stable at the temperature at which the primary argument is made. The reasons can be summarized as follows. Eirst, data are available for the alpha form of $\mathrm{UF}_{5}$ and not for the beta form. Second, the interpolation between $\mathrm{UF}_{4}$ and $\mathrm{UF}_{6}$ was consistent for the entropy of $U_{5}$ in its alpha form. Third, consistency in recalculating values of interest is even more important than accuracy for many calculations. And, finally, it will be seen in the next paragraph that 
the estimation results in consistency with other existing independent values.

Thermal functions for gaseous $\mathrm{UF}_{5}$ can be calculated from spectroscopic data by Jones and Ekberg ${ }^{16}$ whose observations are in accord with calculations by $\mathrm{Krohn}$ et al.17 The structure of the molecule seems to be $\mathrm{C}_{4 \mathrm{~V}}$. The U-F distance is $1.995 \mathrm{~A}$, and the angle beta is $101^{\circ}$. One must add ln 2 to account for one unpaired electron on uranium. Calculation of the entropy of gaseous $\mathrm{UF}_{5}$ can be checked by an alternative calculation, much as for $U_{4}$, and agreement is obtained. The entropy of $U_{5}$ ( $s$ ) has been measured, as mentioned above. Wolf et al. 18 have measured the transport of $\mathrm{UF}_{5}$ in a $\mathrm{UF}_{6}$ atmosphere. Kleinschmidt and Hildenbrand ${ }^{19}$ determined the proportion of $\mathrm{UF}_{5}$ and $\mathrm{U}_{2} \mathrm{~F}_{10}$ in the vapor, and an earlier publication by Leitnaker 20 corrected the data of wolf et al.18 for an effect by $\mathrm{UF}_{6}$ on the amount of $\mathrm{UF}_{5}$ transported. From these data the entropy of vaporization of $\mathrm{UF}_{5}, \Delta S^{\circ} 298 / R$, is calculated to be 22.6 . Adding the entropy of solid $\mathrm{UF}_{5}$, one obtains for gaseous $\mathrm{UF}_{5}$ an entropy, $S^{\circ} 298 / R$, of 45.42 . By use of spectroscopic data, the value for the entropy is calculated to be 45.21 , in excellent agreenent. In addition, the enthalpy of vaporization via the second and third law calculations can be compared by virtue of having free energy functions for both the solid and gas. Using the second law one calculates, for $\mathrm{UF}_{5}$, a value of the enthalpy $\Delta H^{\circ}{ }_{298} / R$, of $18,978 \mathrm{~K}$. Using the third law one obtains $18,855 \mathrm{~K}$. The agreement is excellent.

Thermal functions for gaseous $\mathrm{U}_{2} \mathrm{~F}_{10}$ cannot be calculated directly, for the data do not exist. Nevertheless, a very good approximation to the desired functions can be obtained. The high temperature heat capacity of $\mathrm{U}_{2} \mathrm{~F}_{10}(\mathrm{~g})$ should be approachable through $\mathrm{UF}_{5}(\mathrm{~g})$. In the previous paragraph, we have calculated the thermal function of $\mathrm{UF}_{5}(\mathrm{~g})$ from spectroscopic data and found that the calculated entropy of the gas agreed with that obtained by adding the entropy of vaporization to the entropy of the solid. The fact that the calculations agree tends to substantiate both numbers. Moreover, the agreement suggests that there are no important low lying electronic levels not accounted for in the calculation. classically, the value of $\mathrm{C}_{\mathrm{p}} / \mathrm{R}$ for $\mathrm{UF}_{5}(\mathrm{~g})$ should be 16 . In Table 7 the value at $298 \mathrm{~K}$ is seen to be 13.286 , rising to 15.917 at $2000 \mathrm{~K}$. If it is assumed that $\mathrm{U}_{2} \mathrm{~F}_{10}(\mathrm{~g})$ would behave in a similar way, the value of $\mathrm{C}_{\mathrm{p}} / \mathrm{R}$ for $\mathrm{U}_{2} \mathrm{~F}_{10}(\mathrm{~g})$ at any temperature, $\mathrm{T}$, can be estimated by multiplying the heat capacity of $\mathrm{UF}_{5}(\mathrm{~g})$ at $\mathrm{T}$ by $34 / 16$, where 34 is the classical value for $\mathrm{U}_{2} \mathrm{~F}_{10}$ and 16 is the classical value for $\mathrm{UF}_{5}$. Then, $\left(\mathrm{H}^{\circ} \mathrm{T}-\right.$ $\mathrm{H}^{\circ} 298$ )/ $\mathrm{R}$ can be obtained by integration, as can $\left(\mathrm{S}^{\circ} \mathrm{T}-\mathrm{S}^{\circ} 298\right) / \mathrm{R}$. To get $S^{\circ} 298 / R$ one can use the data of Wolf et al. ${ }^{18}$ on the transport, suitably corrected as described subsequently for $\mathrm{UF}_{5}(g)$. All the functions for $\mathrm{U}_{2} \mathrm{~F}_{10}(\mathrm{~g})$ are tabulated in Table 8 . 
Table 1

THERMODYNAMIC FUNCTIONS FOR CONDENSED URANIUM(a)

\begin{tabular}{|c|c|c|c|c|}
\hline $\mathrm{T}, \mathrm{K}$ & $C_{p} / R$ & $\left(\mathrm{H}^{\circ} \mathrm{T}-\mathrm{H}^{\circ} 298\right) / \mathrm{R}, \mathrm{K}$ & $S^{\circ} T / R$ & $-\left(G^{\circ} T-H^{\circ} 298\right) / R T$ \\
\hline 298.15 & 3.33 & 0 & 6.04 & 6.04 \\
\hline 300 & 3.33 & 6 & 6.06 & 6.04 \\
\hline 400 & 3.57 & 352 & 7.05 & 6.17 \\
\hline 500 & 3.85 & 722 & 7.88 & 6.43 \\
\hline 600 & 4.18 & 1122 & 8.61 & 6.73 \\
\hline 700 & 4.57 & 1560 & 9.28 & 7.05 \\
\hline 800 & 5.03 & 2038 & 9.92 & 7.37 \\
\hline 900 & 5.55 & 2566 & 10.54 & 7.68 \\
\hline $941(\alpha)$ & 5.77 & 2798 & 10.79 & 7.82 \\
\hline $941(B)$ & 5.16 & 3135 & 11.15 & 7.82 \\
\hline 1000 & 5.16 & 3442 & 11.46 & 8.02 \\
\hline $1048(\beta)$ & 5.16 & 3689 & 11.70 & 8.19 \\
\hline $1048(\alpha)$ & 4.60 & 4257 & 12.25 & 8.19 \\
\hline 1100 & 4.60 & 4499 & 12.47 & 8.38 \\
\hline 1200 & 4.60 & 4957 & 12.87 & 8.74 \\
\hline 1300 & 4.60 & 5420 & 13.24 & 9.07 \\
\hline 1400 & 4.60 & 5878 & 13.58 & 9.38 \\
\hline $1405(\alpha)$ & 4.60 & 5903 & 13.60 & 9.40 \\
\hline $1405(l)$ & $(4.60)$ & $(7458)$ & $(14.70)$ & 9.40 \\
\hline 1500 & $(4.60)$ & $(7896)$ & $(15.01)$ & 9.74 \\
\hline 2000 & $(4.60)$ & $(10200)$ & $(16.33)$ & 11.23 \\
\hline
\end{tabular}


Table 2

THERMODYNAMIC FUNCTIONS FOR UF 4 (SOLID) (a)

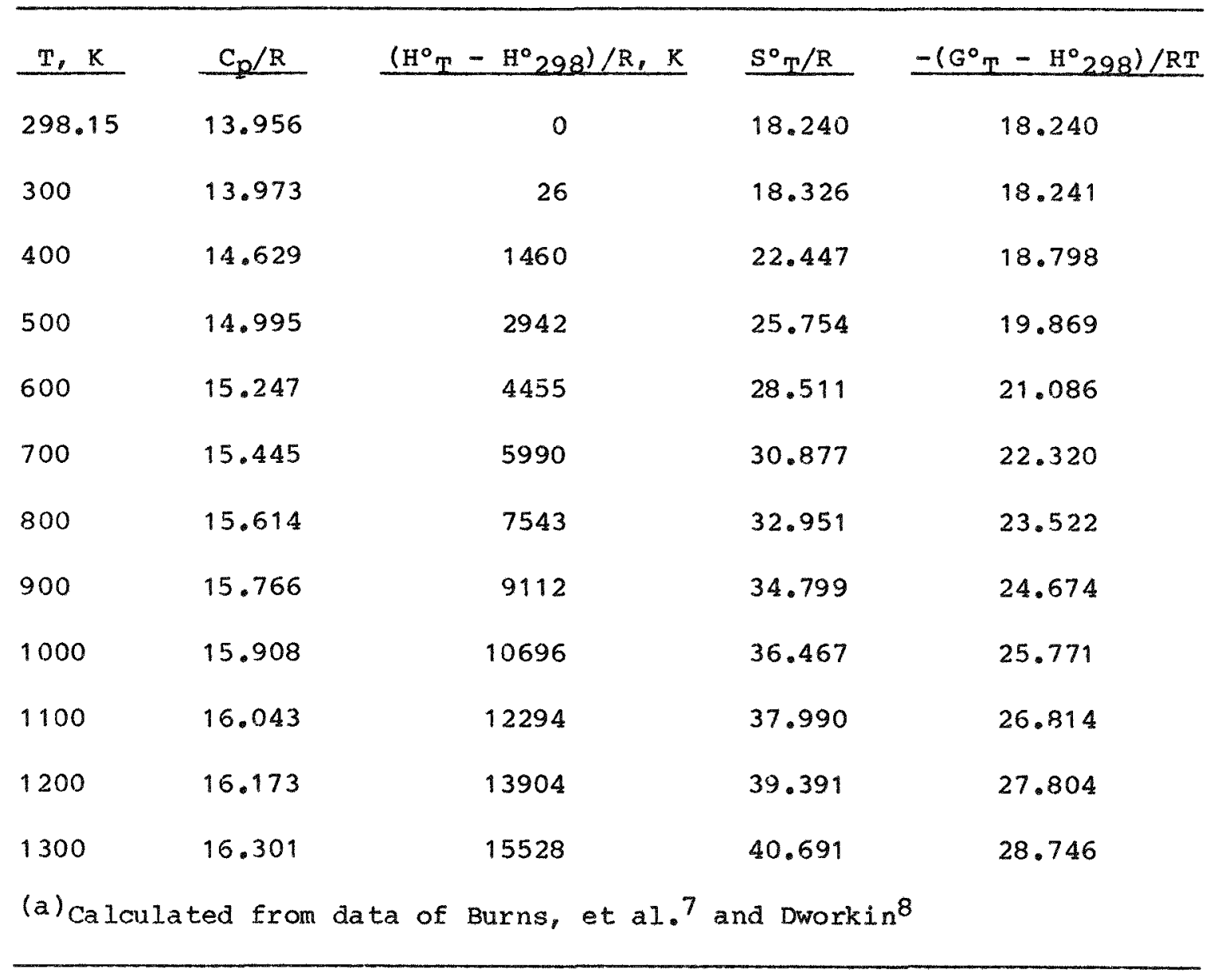


Table 3

THERMODYNAMIC FUNCTIONS FOR UF 4.25 (SOLID) $(a)$

\begin{tabular}{|c|c|c|c|c|}
\hline $\mathrm{T}, \mathrm{K}$ & $C_{p} / R$ & $\left(\mathrm{H}^{\circ} \mathrm{T}-\mathrm{H}^{\circ} 298\right) / \mathrm{R}, \mathrm{K}$ & $S^{\circ} T / R$ & $-\left(G^{\circ} T-H^{\circ} 298\right) / R$ \\
\hline 298.15 & 14.447 & 0 & 19.390 & 19.390 \\
\hline 300 & 14.465 & 27 & 19.479 & 19.391 \\
\hline 400 & 15.144 & 1511 & 23.745 & 19.968 \\
\hline 500 & 15.523 & 3046 & 27.169 & 21.077 \\
\hline 600 & 15.784 & 4612 & 30.023 & 22.336 \\
\hline 700 & 15.989 & 6201 & 32.472 & 23.614 \\
\hline 800 & 16.163 & 7809 & 34.619 & 24.858 \\
\hline 900 & 16.321 & 9433 & 36.532 & 26.051 \\
\hline 1000 & 16.468 & 11073 & 38.259 & 27.186 \\
\hline (a) In & d as & cibed in text. & & \\
\hline
\end{tabular}


Table 4

THERMODYNAMIC FUNCTIONS FOR UF 4.5 (SOLID) (a)

\begin{tabular}{|c|c|c|c|c|}
\hline $\mathrm{T}, \mathrm{K}$ & $C_{p} / R$ & $\left(\mathrm{H}^{\circ} \mathrm{T}-\mathrm{H}^{\circ} 298 / \mathrm{R}, \mathrm{K}\right.$ & $S^{\circ} T / R$ & $-\left(G^{\circ} \mathrm{T}-\mathrm{H}^{\circ} 298\right) / \mathrm{RT}$ \\
\hline 298.15 & 14.938 & 0 & 20.530 & 20.530 \\
\hline 300 & 14.957 & 28 & 20.622 & 20.531 \\
\hline 400 & 15.659 & 1563 & 25.033 & 21.127 \\
\hline 500 & 16.051 & 3150 & 28.573 & 22.274 \\
\hline 600 & 16.321 & 4769 & 31.525 & 23.577 \\
\hline 700 & 16.532 & 6412 & 34.057 & 24.897 \\
\hline 800 & 16.713 & 8074 & 36.276 & 26.184 \\
\hline 900 & 16.876 & 9754 & 38.255 & 27.417 \\
\hline 1000 & 17.028 & 11449 & 40.041 & 28.591 \\
\hline
\end{tabular}


Table 5

THERMODYNAMIC FUNCTIONS FOR UF 5 (ALPHA) (a)

\begin{tabular}{|c|c|c|c|c|}
\hline $\mathrm{T}, \mathrm{K}$ & $C_{p} / R$ & $\left(\mathrm{H}^{\circ} \mathrm{T}-\mathrm{H}^{\circ} 298\right) \mathrm{R}, \mathrm{K}$ & $S^{\circ} \pi / R$ & $-\left(G^{\circ} T-H^{\circ} 298\right) / R T$ \\
\hline 298.15 & 15.919 & 0 & 22.820 & 22.820 \\
\hline 300 & 15.939 & 29 & 22.919 & 22.821 \\
\hline 400 & 16.688 & 1665 & 27.619 & 23.456 \\
\hline 500 & 17.105 & 3356 & 31.391 & 24.679 \\
\hline 600 & 17.392 & 5082 & 34.537 & 26.067 \\
\hline 700 & 17.618 & 6833 & 37.235 & 27.474 \\
\hline 800 & 17.811 & 8604 & 39.601 & 28.845 \\
\hline 900 & 17.984 & 10394 & 41.709 & 30.159 \\
\hline 1000 & 18.146 & 12201 & 43.612 & 31.411 \\
\hline
\end{tabular}


Table 6

THERMODYNAMIC FUNCTIONS FOR UF 6 (SOLID AND LIQUID) (a)

\begin{tabular}{|c|c|c|c|c|}
\hline $\mathrm{T}, \mathrm{K}$ & $C_{p} / R$ & $\left(\mathrm{H}^{\circ} \mathrm{T}-\mathrm{H}^{\circ} 298\right) / \mathrm{R}, \mathrm{K}$ & $S^{\circ} r / R$ & $-\left(\mathrm{G}^{\circ} \mathrm{T}-\mathrm{H}^{\circ} 298\right) / \mathrm{RT}$ \\
\hline 298 & 20.06 & 0 & 27.40 & 27.40 \\
\hline 300 & 20.13 & 37 & 27.53 & 27.40 \\
\hline 310 & 20.57 & 241 & 28.20 & 27.42 \\
\hline 320 & 21.04 & 449 & 28.86 & 27.46 \\
\hline 330 & 21.53 & 662 & 29.51 & 27.51 \\
\hline $337.212(5)$ & 21.89 & 819 & 29.98 & 27.55 \\
\hline $337.212(1)$ & 22.95 & 3128 & 36.83 & 27.55 \\
\hline 340 & 22.99 & 3192 & 37.02 & 27.63 \\
\hline 350 & 23.16 & 3424 & 37.69 & 27.91 \\
\hline 360 & 23.32 & 3657 & 38.34 & 28.18 \\
\hline 370 & 23.46 & 3892 & 38.98 & 28.46 \\
\hline \multicolumn{5}{|c|}{ (a) Calculated from data by Brickwedde, et al. ${ }^{4}$} \\
\hline
\end{tabular}


Table 7

THERMODYNAMIC FUNCTIONS FOR UF 5 (GAS) (a)

\begin{tabular}{|c|c|c|c|c|}
\hline $\mathrm{T}, \mathrm{K}$ & $C_{p} / R$ & $\left(\mathrm{H}^{\circ} \mathrm{T}-\mathrm{H}^{\circ} 298\right) / \mathrm{R}, \mathrm{K}$ & $\underline{S^{\circ} T / R}$ & $-\left(G^{\circ} T-H^{\circ} 298\right) / R T$ \\
\hline 298.15 & 13.286 & 0 & 45.214 & 45.214 \\
\hline 300 & 13.319 & 25 & 45.297 & 45.214 \\
\hline 400 & 14.278 & 1409 & 49.272 & 45.750 \\
\hline 500 & 14.824 & 2867 & 52.522 & 46.790 \\
\hline 600 & 15.153 & 4367 & 55.257 & 47.979 \\
\hline 700 & 15.363 & 5893 & 57.609 & 49.191 \\
\hline 800 & 15.505 & 7437 & 59.671 & 50.375 \\
\hline 900 & 15.605 & 8993 & 61.503 & 51.511 \\
\hline 1000 & 15.678 & 10557 & 63.151 & 52.594 \\
\hline 1100 & 15.732 & 12128 & 64.648 & 53.623 \\
\hline 1200 & 15.774 & 13703 & 66.019 & 54.600 \\
\hline 1300 & 15.807 & 15283 & 67.283 & 55.528 \\
\hline 1400 & 15.833 & 16865 & 68.455 & 56.410 \\
\hline 1500 & 15.854 & 18449 & 69.548 & 57.250 \\
\hline 1600 & 15.872 & 20035 & 70.572 & 58.051 \\
\hline 1700 & 15.886 & 21623 & 71.535 & 58.816 \\
\hline 1800 & 15.898 & 23212 & 72.443 & 59.548 \\
\hline 1900 & 15.909 & 24803 & 73.303 & 60.250 \\
\hline 2000 & 15.917 & 26394 & 74.119 & 60.923 \\
\hline
\end{tabular}

(a) Calculated from vibrational data by Jones and Ekberg ${ }^{16}$ 


\section{Table 8}

THERMODYNAMIC FUNCTIONS FOR $\mathrm{U}_{2} \mathrm{~F}_{10}$ (GAS) (a)

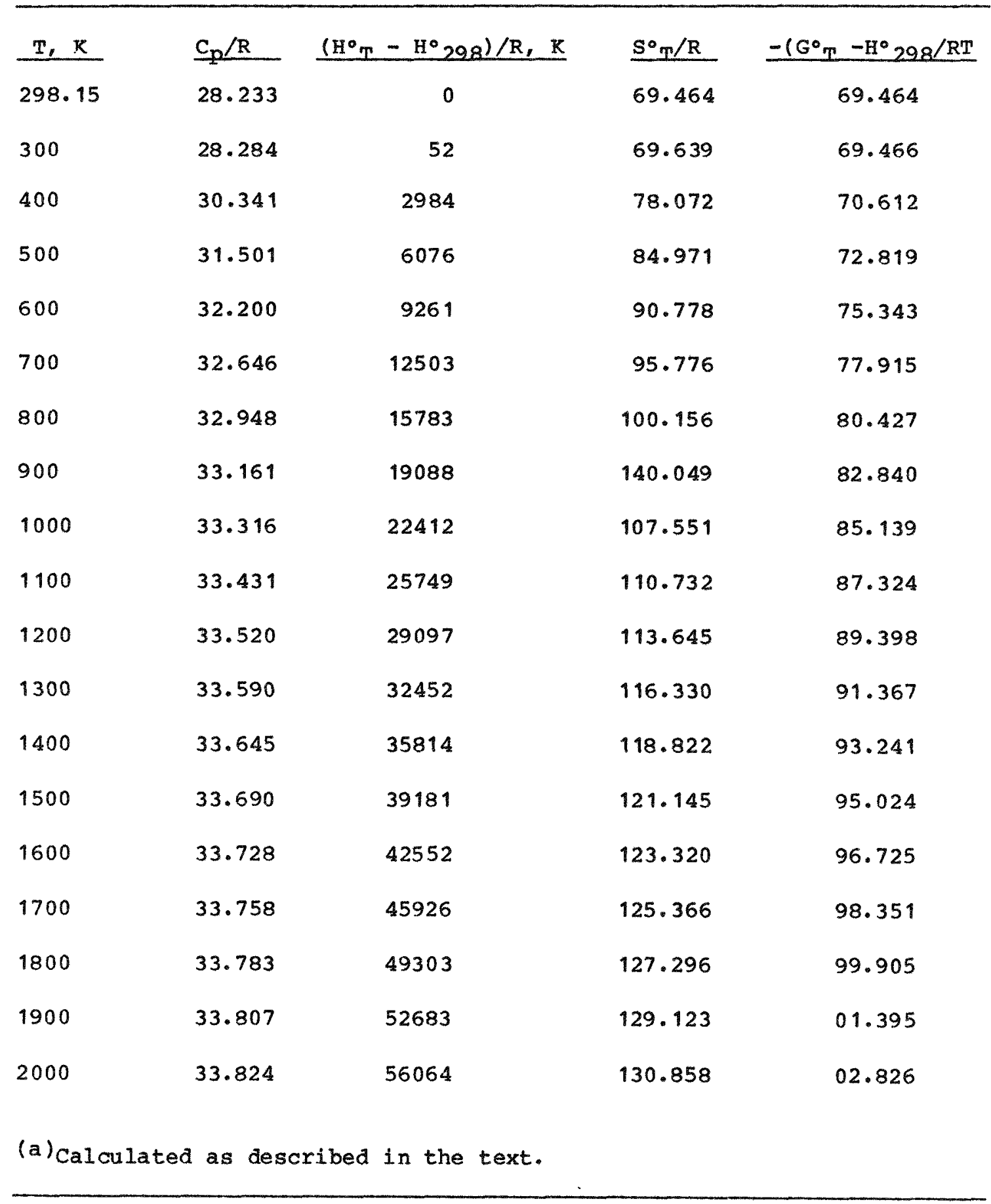


Table 9

THERMODYNAMIC FUNCTIONS FOR UF 6 (GAS) (a)

\begin{tabular}{|c|c|c|c|c|}
\hline$T, K$ & $C_{p} / R$ & $\left(\mathrm{H}^{\circ} \mathrm{m}-\mathrm{H}^{\circ} 298\right) / \mathrm{R}, \mathrm{K}$ & $\underline{S^{\circ} T / R}$ & $-\left(G^{\circ} \mathrm{T}-\mathrm{H}^{\circ} 298\right) / \mathrm{RT}$ \\
\hline 298.15 & 15.593 & 0 & 45.401 & 45.401 \\
\hline 300 & 15.623 & 29 & 45.498 & 45.402 \\
\hline 400 & 16.826 & 1657 & 50.174 & 46.031 \\
\hline 500 & 17.511 & 3377 & 54.009 & 47.255 \\
\hline 600 & 17.925 & 5150 & 57.241 & 48.657 \\
\hline 700 & 18.191 & 6957 & 60.026 & 50.087 \\
\hline 800 & 18.371 & 8786 & 62.467 & 51.485 \\
\hline 900 & 18.497 & 10629 & 64.639 & 52.828 \\
\hline 1000 & 18.590 & 12484 & 66.593 & 54.108 \\
\hline 1100 & 18.659 & 14347 & 68.368 & 55.325 \\
\hline 1200 & 18.712 & 16215 & 69.994 & 56.481 \\
\hline 1300 & 18.754 & 18089 & 71.493 & 57.578 \\
\hline 1400 & 18.787 & 19966 & $72 \cdot 884$ & 58.623 \\
\hline 1500 & 18.814 & 21846 & 74.181 & 59.617 \\
\hline 1600 & 18.836 & 23729 & 75.396 & 60.566 \\
\hline 1700 & 18.855 & 25613 & 76.539 & 61.472 \\
\hline 1800 & 18.870 & 27499 & 77.617 & 62.339 \\
\hline 1900 & 18.884 & 29387 & 78.638 & 63.170 \\
\hline 2000 & 18.895 & 31276 & 79.607 & 63.968 \\
\hline (a) & i & of Weinstock, & & \\
\hline
\end{tabular}


Table 10

THERMODYNAMIC FUNCTIONS FOR $\mathrm{F}_{2}$ (GAS) (a)

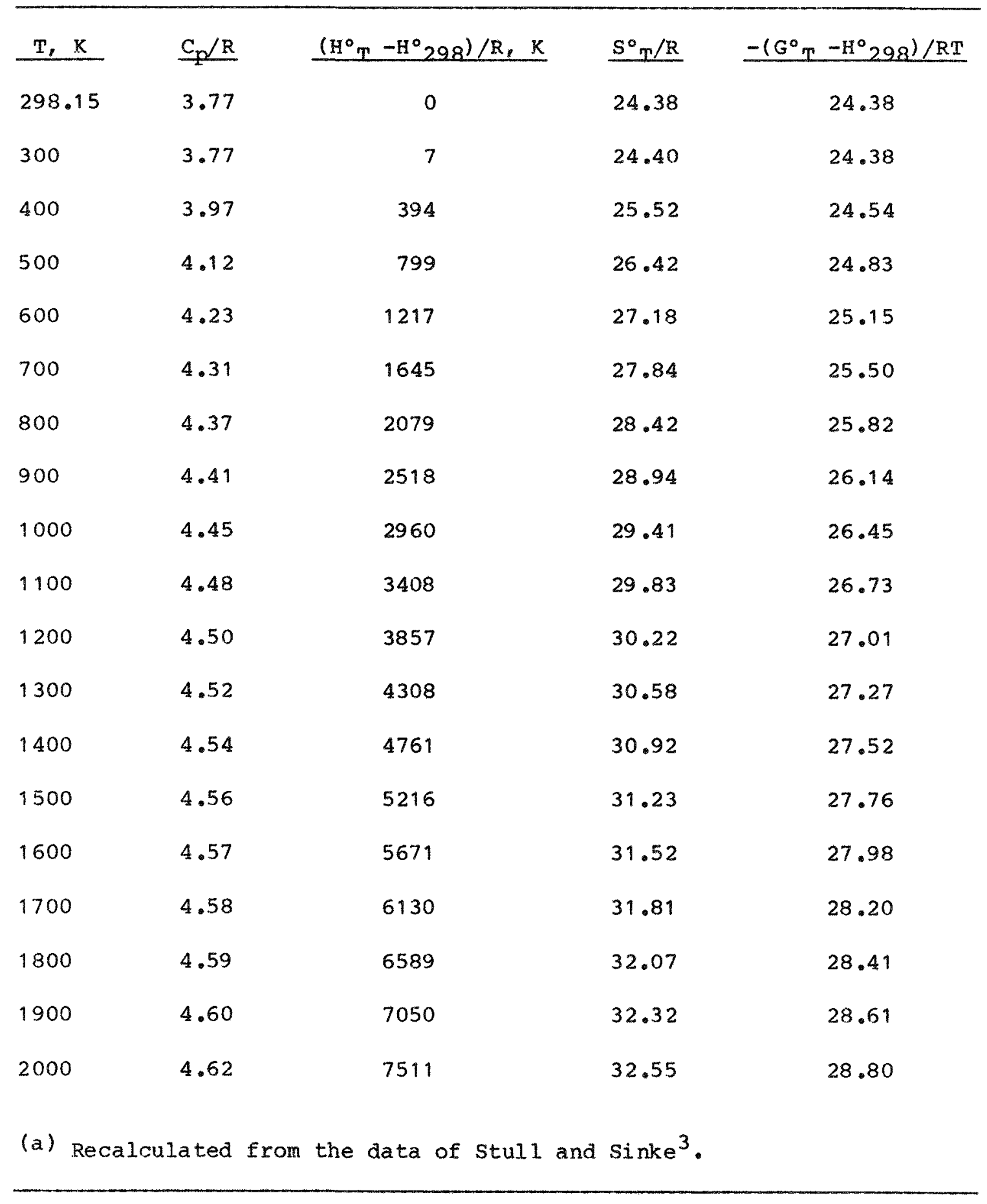


Data of Wolf et a1.18

The vapor pressure of uranium pentafluoride cannot be determined, for example, by means of a Knudsen cell measurement, because the pentafluoride loses $\mathrm{UF}_{6}(\mathrm{~g})$ preferentially on heating, However, by using UF6 as a transporting gas one can prevent the disproportionation and determine the vapor transport of $\mathrm{UF}_{5}$. Wolf 18 and co-workers performed this measurement a number of years ago.

From the measurement of the transport the pressure of the pentafluoride could be calculated by the formula

$$
\mathbb{P}_{\mathrm{UF}_{5}}=\mathrm{N}_{\mathrm{UF}_{5}} \times \mathrm{P}_{\mathrm{UF}_{6}} / \mathrm{N}_{\mathrm{UF}}
$$

where $P_{U F_{5}}$ and $P_{U F_{6}}$ are the vapor pressures of the pentafluoride and hexafluoride and the N's represent the number of moles of the two materials transported.

Enhanced Transport by Uranium Hexafluoride

Reevaluation of the data reported by Wolf et al. 18 indicated that the UF6 was providing a mechanism of transporting the UF 5.20 When the data were tested against the equation

$$
\ln " \mathrm{P}_{\mathrm{UF}}{ }_{5} "=a_{0}+a_{1}(1 / T)+a_{2} P_{U F_{6}}
$$

the constant $a_{2}$ was shown to be statistically significant, especially when the UF5 was solid.

The reason for the enhanced transport is not now clear. A first conjecture was that the process

$$
\mathrm{UF}_{5}(\mathrm{~s})+\mathrm{UF}_{6}(g)=\mathrm{U}_{2} \mathrm{~F}_{11}(g)
$$

or possibly

$$
\mathrm{UF}_{5}(\mathrm{~s})+\mathrm{x} \mathrm{UF}_{6}(g)=\mathrm{UF}_{5} \cdot\left(\mathrm{UF}_{6}\right)_{\mathrm{X}}(\mathrm{g})
$$

produced the enhanced transport. (The $\mathrm{U}_{2} \mathrm{~F}_{11}$ simply represents the simplest combination of solid UF5 and gaseous $\mathrm{UF}_{6}$ to produce a gaseous molecule-and $\mathrm{UF}_{5} \cdot\left(\mathrm{UF}_{6}\right)_{x}$ represents the general possibility.) The existence of such a molecule is certainly not outside the realm of possibility. The ion-molecule $\mathrm{U}_{2} \mathrm{~F}_{1} 1^{+}$has been observed in the mass spectrometer, 19 although it is not clear whether it formed in a reaction, such as between an ion and a molecule, or if it was present as a parent ion. The presence of such a molecule would explain the observed enhancement. Notice that as the pressure of $\mathrm{UF}_{6}$ increases the pressure of the gaseous adduct also would increase. 
However, the explanation above is not the only way in which additional transport could be produced by an increased pressure of $\mathrm{UF}_{6}$. Such a process could occur via the reaction

$$
\mathrm{UO}_{2} \mathrm{~F}_{2}(\mathrm{~s})+\mathrm{UF}_{6}(g)=2 \mathrm{UOF}_{4}(g) \text {. }
$$

It is extremely difficult to prevent small traces of moisture from contaminating the system, particularly during assembly and disassembly, and this could provide the required $\mathrm{UO}_{2} \mathrm{~F}_{2}$ via the reaction

$$
\mathrm{UF}_{6}+2 \mathrm{H}_{2} \mathrm{O}=\mathrm{UO}_{2} \mathrm{~F}_{2}+4 \mathrm{HF}
$$

Very little is known about the thermodynamics of UOF $_{4}$ and nothing about the gaseous state. Only fragmentary references to the gas are found in the literature.

\section{Gaseous Polymers of Uranium Pentafluoride}

A recent mass spectrometxic examination of the vaporization behavior of a $\mathrm{UF}_{\mathrm{X}}$ solid, somewhat richer in fluorine than $\mathrm{UF}_{4}$ but of unknown exact composition, by Kleinschmidt and Hildenbrand, 19 revealed that the most important species in the gas over $\mathrm{UF}_{5}$--other than $\mathrm{UF}_{6}$-was $\mathrm{U}_{2} \mathrm{~F}_{10}$ rather than the monomeric $\mathrm{UF}_{5}$. No other polymers were seen, although in the Mo-F system polymers have been seen of the formula $\left(M_{5} F_{5}\right)_{n}$ with $n$ from 1 to 5 inclusive. 21 In the $W-F$ system the pentafluoride polymers seen include the tetramer but not the pentamer. 22

The presence of polymeric $\mathrm{UF}_{5}$ in the vapor phase necessitates correction of the vapor pressures measured by Wolf et al. ${ }^{18}$ not only for the enhancement of transport by the $\mathrm{UF}_{6}$ but also for the dimerization. It is for this reason that quotation marks were put around $\mathrm{P}_{\mathrm{UF}_{5}}$ in Equation ( 3 ). Note particularly in Equation (2) that the $\mathrm{N}_{U F_{5}}$ requires a molecular weight to calculate its value from the mass of UF transported.

\section{Vapor Pressure Equations for Pentafluoride}

There is still uncertainty about the cause of the additional transport seen, via UF 6 , for the pentafluoride. Nevertheless, the data available can be usefully described with equations. The raw transport data of Wolf et al.18 for solid $U_{5}$ have been fitted by use of Equation (3), obtaining

$$
\ln " \mathrm{P}_{\mathrm{UF}_{5}} \text { " }=-16.93( \pm 0.41) \times 10^{3} / \mathrm{T}+22.47( \pm 0.76)+
$$

where the unit of pressure is atmospheres and $T$ is in kelvin.

The quotation marks around $\mathrm{P}_{U F_{5}}$ emphasize this is not really a pressure but an effective pressure calculated assuming all the transported $\mathrm{UF}_{5}$ was present as a monomex in the gas phase.

If $\mathrm{PUF}_{6}$ is set equal to zero, one obtains 


$$
\ln " \mathrm{P}_{\mathrm{UF}_{5}} "=-16,930 / \mathrm{T}+22.47,
$$

which represents the transport of $\mathrm{UF}_{5}$ unaided by $\mathrm{UF}_{6}$.

To obtain pressure equations, one must draw on the data of Kleinschmidt and Hildenbrand ${ }^{8}$ which related the equilibria of

$$
2 \mathrm{UF}_{5}(g)=\mathrm{U}_{2} \mathrm{~F}_{10}(g)
$$

as

$$
\ln \left[P_{U_{2} F_{10}} /\left(P_{U_{F}}\right)^{2}\right]=\ln K=19,625 / \mathrm{T}-20.15
$$

Recall that

$$
\begin{aligned}
\text { wt } \mathrm{UF}_{5} \text { (measured) = } & \text { wt } \mathrm{UF}_{5} \text { (transported) + } \\
& \text { wt } \mathrm{U}_{2} \mathrm{~F}_{10} \text { (transported). }
\end{aligned}
$$

From the gas law

$$
\begin{aligned}
& \text { "PUF } 5 " \cdot \mathrm{MUF}_{5} \cdot(\mathrm{V} / \mathrm{RT})=\mathrm{PUF}_{5} \cdot \mathrm{MUF}_{5} \cdot(\mathrm{V} / \mathrm{RT})+ \\
& \mathrm{PU}_{2} \mathrm{~F}_{10} \cdot \mathrm{MU}_{2} \mathrm{~F}_{10} \cdot(\mathrm{V} / \mathrm{R} T)
\end{aligned}
$$

A simple substitution and cancellation yields

$$
\text { "P } \mathrm{P}_{\mathrm{UF}_{5}} "=\mathrm{PUF}_{5}+2 \mathrm{P}_{\mathrm{U}_{2}} \mathrm{~F}_{10}
$$

Combination of Equations (9), (11), and (14) yield the equations

$$
\ln \mathrm{P}_{\mathrm{U}_{2}} \mathrm{E}_{10}=-16,900 / \mathrm{T}+21.704
$$

and

$$
\ln P_{U F_{5}}=-18,263 / T+20.926
$$

These last two equations represent the best present estimation of the pressures of the two known pentafluoride species over solid $\mathrm{UF}_{5}$ in the range of the measurements.

There is an interesting historical note related to these pressures. Brewer et al. estimated the pressure of the pentafluoride in the early $40 \mathrm{~s}$ in connection with the Manhattan Project. In Figure 1 the relationship among the various pressures referred to is shown. The highest pressures are those reported by wolf et al. 18 which, as mentioned previously, are really transport values. The next lowex line represents these transport values corrected for the effect of $\mathrm{UF}_{6}$ on the measurements. The next line represents the pressure of $\mathrm{U}_{2} \mathrm{~F}_{10}$ computed from a combination of the data of Kleinschmidt and Hildenbrand ${ }^{19}$ and of wolf et a1. 18. The lowest line represents the pressure of $\mathrm{UF}_{5}$ estimated by Brewer and superimposed on the line is a point representing the calculated pressure of the gaseous monomer of $\mathrm{UF}_{5}$ at its melting point, indicating 


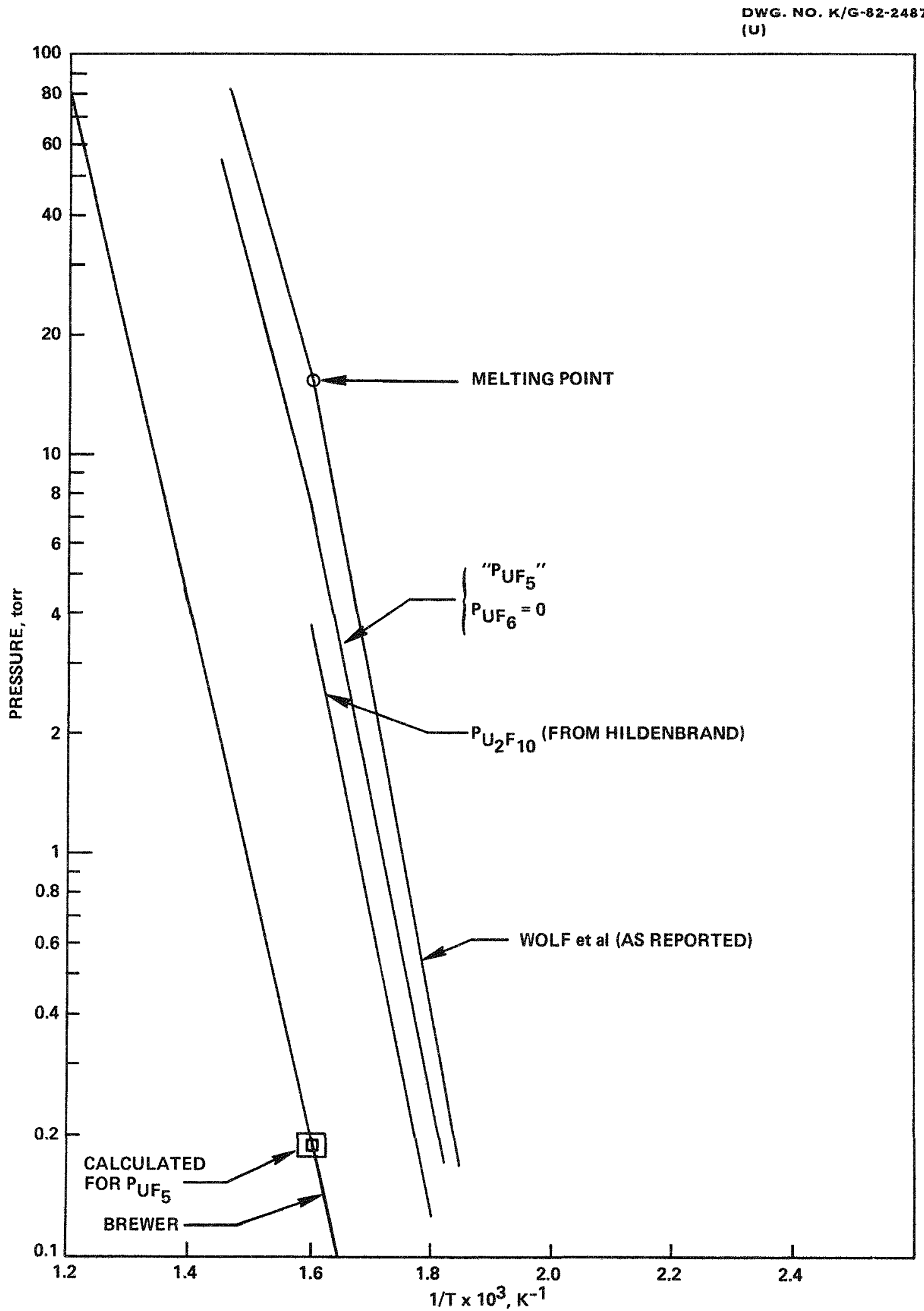

Figure 1

PRESSURE-TEMPERATURE RELATIONSHIPS OF "UF ${ }_{5}$ " SPECIES 
Brewex was nearly correct in his estimation of the pressure of the monomer. It was several years later that the importance of polymeric gaseous halides was recognized.

\section{ENTHALPIES OE EORMATION OF URANIUM FLUORIDES}

The Heat of Formation of UFG and UF 4

Johnson 23 has recently redetermined the heat of formation of uranium hexafluoride, obtaining $-2197.7 \pm 1.8 \mathrm{~kJ} \mathrm{~mol}^{-1}$ and $-2148.1 \pm 1.8 \mathrm{~kJ} \mathrm{~mol}^{-1}$ for $\mathrm{UF}_{6}(\mathrm{c})$ and $\mathrm{UF}_{6}(\mathrm{~g})$, respectively, at $298.15 \mathrm{~K}$. This value was consistent with a previous finding by Johnson and $0^{\prime} \mathrm{Hare}^{24}$ that the enthalpy of $\mathrm{U}_{3}$, as determined by calorimetry, would be consistent with other thermodynamic measurements if the value for the enthalpy of formation of the hexafluoride were in exror by about $11 \mathrm{~kJ}$ mol-1. The $\mathrm{UO}_{3}$ work was solution calorimetry and the $\mathrm{UF}_{6}$ investigation consisted of combustion in a bomb calorimeter.

Previous measurements, which differed from the results of Johnson given above, had also been consistent, however, and the consistency of the latest results is no guarantee of accuracy. Nevertheless, we have adopted these nore recent values. Additional calculations lend strength to the new values, albeit indirectly.

Another quantity determined by Johnson 25 bears importantly on that which follows this section. Johnson determined calorimetrically the enthalpy of formation of $\mathrm{UF}_{4}$. His value was $-1910.4+2.1 \mathrm{~kJ} \mathrm{~mol}^{-1}$ for the enthalpy of formation at $298.15 \mathrm{~K}$. These values can be used to recalculate the results of Agron ${ }^{2}$ which is done in the next section.

Recalculation of Thermodynamic Data from Equilibrium Pressures of $\mathrm{UF}_{6}(\mathrm{~g})$ over Intermediate Fluorides

All four fluorides of uranium between $U_{6}$ and $U_{4}$ lose $_{4} \mathrm{UF}_{6}$ preferentially on heating in a vacuum. The stepwise reactions are:

$$
\begin{aligned}
3 a-U F_{5}(s) & =U_{2} F_{9}(s)+U F_{6}(g), \\
3 B-U F_{5}(s) & =U_{2} F_{9}(s)+U F_{6}(g), \\
7 / 2 U_{2} F_{9}(s)= & 3 / 2 U_{4} F_{17}(s)+U F_{6}(g),
\end{aligned}
$$

and

$$
2 U_{4} F_{17}(s)=7 \mathrm{UF}_{4}(s)+\mathrm{UF}_{6}(g) \text {. }
$$

Equilibrium pressures of $\mathrm{UF}_{6}$ for Reactions $(17)-(20)$ were measured a number of years ago by Agron. 14 In this section, the data obtained by Agron are re-examined by both the second and third law methods. 
Results of vaporization studies, almost always performed as a function of temperature, are customarily tabulated by considering the logarithm of the measured pressure as an inverse function of the absolute temperature, via the well-known Clausius-Clapeyron equation. This treatment is frequently known as the "second law" method; one obtains the enthalpy of the reaction from the slope of the line and the entropy from the intercept with the ordinate, extrapolated to (1/T) equals zero. The method is useful, but has the disadvantage that, if the range of measurements is short, small errors, particularly temperature-dependent ones, are magnified and large errors often much greater than the observed statistical precision, can be obtained in both the enthalpy and the entropy.

A somewhat more sophisticated method, when the heat capacity change, $\Delta c_{p}$, for the reactions studied is known, is available. One uses the equation

$$
\Sigma=\left[-\ln K+\frac{\Delta C_{P}}{R}(-\ln T+\theta / T)\right]=\frac{\Delta H^{\circ} \Theta}{R}(1 / T)+I
$$

to obtain $\Delta \mathrm{H}^{\circ} \theta$ at some fixed temperature, $\theta$, where $\mathrm{K}$ is the equilibrium constant for the reaction studied and $R$ is the gas constant. I is a constant of integration and is related to the entropy for the process via

$$
\Delta S^{\circ} \theta / R=\left(\Delta C_{p} / R\right)(1+\ln \theta)-I
$$

The fixed temperature, $\theta$, is usually chosen near the temperature of measurement so that treating $\Delta c_{p}$ as a constant is a good approximation. While this treatment was employed, it offers little advantage over the "second law" method described above for the relatively small temperature ranges studied by Agron.

A better method of treating vapor pressure data, when thermal data are available, is the so-called "third law" method. Here the change in standard free energy for the process is calculated for each point and the thermal data are used to normalize the answers to some standard temperature by calculation of the enthalpy, usually $\Delta \mathrm{H}^{\circ} 298^{\circ}$. An equation normally used is

$$
\Delta H^{\circ}{ }_{298}=\Delta G^{\circ} T-T\left[\Delta\left(G^{\circ}{ }_{T}-H^{\circ} 298\right) / T\right]
$$

where

$$
\Delta G^{\circ}{ }_{T}=-R T \ln K
$$

for the process and $\Delta\left(G^{\circ} \mathrm{T}-H^{\circ} 298\right) / T$ is the change in the free energy function for the process under consideration. The free energy functions change slowly with temperature, interpolation is easy, and the process is almost always both more accurate and more precise than the "second law" 
calculation. A disadvantage is that the entropy for the process must be known, either by measurement or reliable estimation, rather than being calculated from the measurements as for the second law process.

The free energy functions, usually tabulated as the negative because the function itself is negative, are more readily visualized when re-arranged. Note that

$$
\begin{gathered}
\frac{\mathrm{G}^{\circ}{ }_{\mathrm{T}}-\mathrm{H}^{\circ} 298}{\mathrm{~T}}=\frac{\mathrm{H}_{\mathrm{T}}{ }_{\mathrm{T}}-\mathrm{TS}{ }^{\circ}{ }_{\mathrm{T}}-\mathrm{H}^{\circ} 298}{\mathrm{~T}} \\
=\frac{{ }^{\circ}{ }_{\mathrm{T}}-\mathrm{H}^{\circ} 298}{\mathrm{~T}}-\mathrm{S}_{\mathrm{T}}^{\circ}
\end{gathered}
$$

and if no transitions occur,

$$
\frac{\int_{298 C_{p} d T}^{T}}{T}-\int_{298}^{T} \frac{C_{p}}{T} d T-S_{298}^{\circ}
$$

The function is controlled numerically, to an important degree, by $S^{\circ} 298^{\circ}$ This is true because the other two terms of equation (26) are of opposite sign and tend to cancel. It is for this reason that the function changes so slowly with temperature and hence is so powerful a tool in examining trends. Notice that if a phase change occurs at a temperature, $\theta$,

$$
\frac{\Delta H_{\text {transition }}}{\theta}=\Delta S_{\text {transition. }}
$$

Consequently, the two terms cancel in Equation (25), and

$$
\left(G^{\circ} T-H^{\circ} 298^{/ T}\right)_{\alpha}=\left(G^{\circ} T-H^{\circ} 298^{\prime T}\right)_{\beta}
$$

at $T=\theta$

Equations (27) and (28) would have been appropriate if the usual procedure for treating a substance with a txansition temperature had been used. They were not used in this treatment for UF 5 as explained above. It is important that this caveat be repeated, since the treatment used here has been non-standard.

The recalculation of Agron's 14 data (Table 11) reveals good agreement of the second law calculation with that given by Agron, except for reaction (19). The other differences are slight and arise almost entirely from the fact that Agron assumed $\Delta c_{p}$ of all the reactions was negligible. Agron's calculation of reaction (19) resulted from a weighting of data which we did not use. 
There are significant differences between values calculated for reactions (17) through (20) using the second and third law methods. Note that the $\Delta S^{\circ} 298 / R$ third law values are essentially the same, except for reaction (18). The reason is the method of estimation, since each reaction is written as a vaporization of one mole of gaseous $\mathrm{UF}_{6}$. The small differences that exist are the result of propagation of rounding errors.

There is clearly a difference between the entropy calculated via the second law and that estimated for the third law calculation. In each reaction the change in entropy may be viewed as that for the change of one mole of solid $\mathrm{UF}_{6}$ to one mole of gaseous $\mathrm{UF}_{6}$. There seems to be no reason why $\Delta S^{\circ} 298 / R$ for these reactions should vary from a low of 11.69 to a high of 23.67 , as the second law calculations indicate. There are two principal reasons why second law values could be at variance with those calculated via the third law. The first is that small errors in the temperature, particularly if the errors are temperature-dependent, are magnified in determining a slope and intercept. A second problem is that the compositions of the solid phases involved in the reactions are assumed to be constant. A changing composition of one or both phases involved would obviously vary the pressure relative to that expected at a constant temperature. In any case, one should expect a smoothly varying entropy among the three reactions (17), (19), and (20). The variation in the calculated second law entropy between Reactions (17) and (20) is inexplicable on chemical grounds. For these reasons, the third law estimated entropies are preferred over the entropies calculated using the second law. As a consequence of this acceptance, the enthalpies calculated using the third law are also preferred over those calculated using the second law.

From data discussed in the previous section, one can now calculate the enthalpies of formation of the intermediate fluorides $\mathrm{U}_{4} \mathrm{~F}_{17}, \mathrm{U}_{2} \mathrm{~F}_{9}$, and UF5. One needs the enthalpy of formation of $\mathrm{UF}_{6}(\mathrm{~g})$,

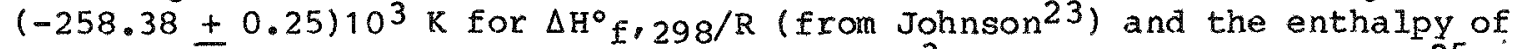
formation of $\left.\mathrm{UF}_{4}(\mathrm{~s}),(-229.77) \pm 0.25\right) 10^{3} \mathrm{~K}$ (also from Johnson 25): Results of the calculation are given in Table 12 based on the second and third law calculations from table 11.

One sees in Table 12 that the enthalpy values calculated are relatively insensitive to variations in values employed in the calculation for reactions (17)-(20). Notice the rather small difference per gram atom of uranium in the enthalpy values for the different compounds relative to the absolute size of the number. This means that the difference between the heats of formation of these compounds is more significant in some cases than the absolute value and emphasizes the necessity for using consistent values.

O'Hare et al. 15 have recently determined, by solution calorimetry, the enthalpies of formation of both $\beta-U F_{5}$ and $\alpha-U F_{5}$. The values for $\Delta H^{\circ} 298 / R$ were $(-250.53 \pm 0.77) \times 10^{3} \mathrm{~K}$ and $(-249.63 \pm 0.81) \times 10^{3} \mathrm{k}$, respectively. The agreement with the values calculated in Table 12 is 
Table 11

RECALCULATED ENTHALPIES AND ENTROPIES OF DECOMPOSITION OF INTERMEDIATE FLUORIDES

\begin{tabular}{|c|c|c|c|c|c|c|}
\hline \multirow[b]{2}{*}{ Equation } & \multicolumn{2}{|c|}{ Second Law } & \multicolumn{2}{|c|}{ Third Law } & \multicolumn{2}{|c|}{ Agron } \\
\hline & $\begin{array}{c}\mathrm{H}^{\circ}{ }_{2}^{29 B} / \mathrm{R} \\
\mathrm{K} \\
\end{array}$ & $\Delta S^{\circ} 298^{/ R}$ & $\begin{array}{c}\Delta \mathrm{H}^{\circ}{ }_{298} / \mathrm{R} \\
\mathrm{K} \\
\end{array}$ & $\Delta S^{\circ} 298^{/ R}$ & $\begin{array}{c}\Delta \mathrm{H}^{\circ} 298^{\prime / R} \\
\mathrm{~K}\end{array}$ & $\Delta s^{\circ} 298^{/ R}$ \\
\hline (17) & 7038 & 11.69 & 9766 & 18.01 & 6774 & 10.92 \\
\hline (18) & 9977 & 19.07 & 12452 & 24.64 & 9592 & 18.02 \\
\hline (19) & 15785 & 23.28 & 12860 & 18.03 & 16844 & 24.86 \\
\hline$(20)$ & 16785 & 23.67 & 13457 & 17.96 & 16447 & 22.75 \\
\hline
\end{tabular}


Table 12

ENTHALPIES OF FORMATION OF INTERMEDIATE URANIUM FLUORIDES (a)

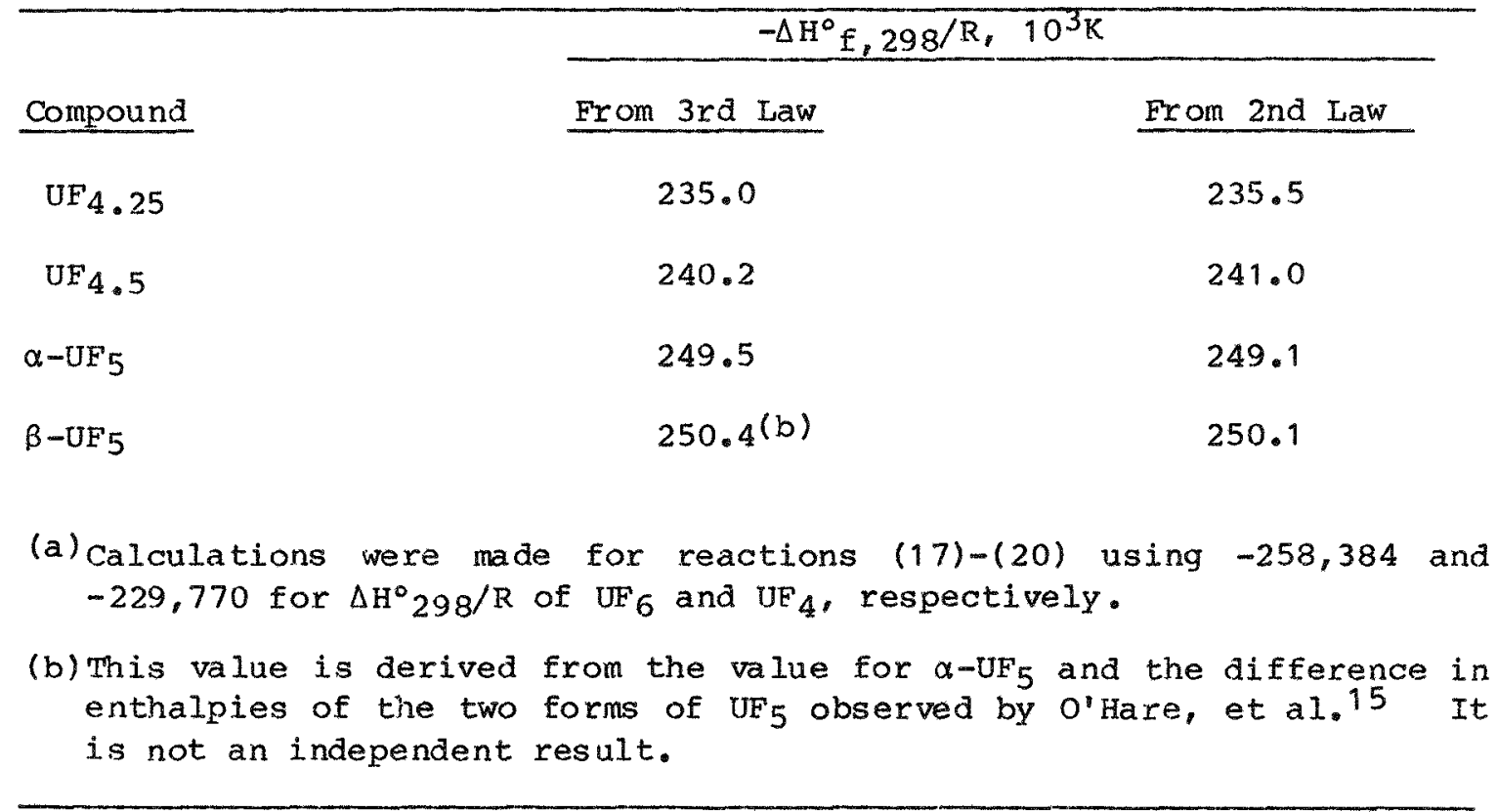


excellent. One must consider the extremely close agreement as, at least in part, fortuitous, since the absolute exrors are considerably greater. Note that it is only the agreement between the two determinations of the alpha form of $U_{5}$ that is being discussed, for the difference found by o'Hare between alpha and beta was arbitrarily put into this calculation. Another way of stating the finding is that $O^{\prime} H a r e ' s$ value for $\alpha-U_{5}$ is confirmed if you choose Johnson's 25 value for the enthalpy of formation of $\mathrm{UF}_{4}$ and Johnson's ${ }^{23}$ value for the enthalpy of formation of $\mathrm{UF}_{6}(g)$.

The second law results of Agron, Table 11, can be used to check the diffexences between the enthalpies of formation of the two forms of $\mathrm{UF}_{5}$. subtraction of reaction (18) from reaction (17) gives three times the enthalpy (and entropy) for the transformation of alpha to beta. For the enthalpy difference one obtains $0.98 \times 10^{3} \mathrm{~K}$ and for the entropy difference, 2.26; these may be compared to the values of $0.90 \times 10^{3} \mathrm{~K}$ and 2.21 (calculated) from O"Hare.

The agreement is good, but, as indicated above, must be regarded in part as fortuitous. Errors, (if they existed) in Agron's temperatures and variations in composition of $\mathrm{U}_{2} \mathrm{~F}_{9}$, if present, would tend to cancel in the subtraction performed above.

The enthalpies of formation and entropies selected for all the uranium fluorine compounds are tabulated in Table 13.

VAPORIZATION BEHAVIOR OF THE URANIUM - FLUORIDE SYSTEM

The Pressure-Composition Diagram

In a previous section the pressure of $\mathrm{UF}_{6}$ over the various intermediate fluorides was described in quantitative terms based on the work of Agron.9 The pressure-composition diagram more clearly relates the various compounds and the composition of the gas phase over the solids. The diagram is shown in Figure 2 and explained in the following paragraphs.

Few scientists are familiar with the diagram shown in Figure 2. Actually, the general features are quite simple and are relatable to the more familiar temperature-composition diagram, appearing only to be turned upside down. Note that the compositions of the condensed phases are shown along the abscissa as line compounds and are at the "ideal" composition, cloaking our ignorance somewhat. The ordinate is pressure on a logarithmic scale and begins at one atmosphere. Because of the scale and to show some of the important features, there are two "breaks" in the diagram; between $\ln \mathrm{P}$ of -38 and -102 and between a mole fraction of Eluorine of 0.75 and 0.80 . No essential information is thereby lost.

The more specific details show the tie lines of the phases of interest at a fixed temperature of $298 \mathrm{~K}$. Consider some of the two phase regions: In the region between $U_{2} F_{9}$ and UE 5 but above $\ln P$ of about 


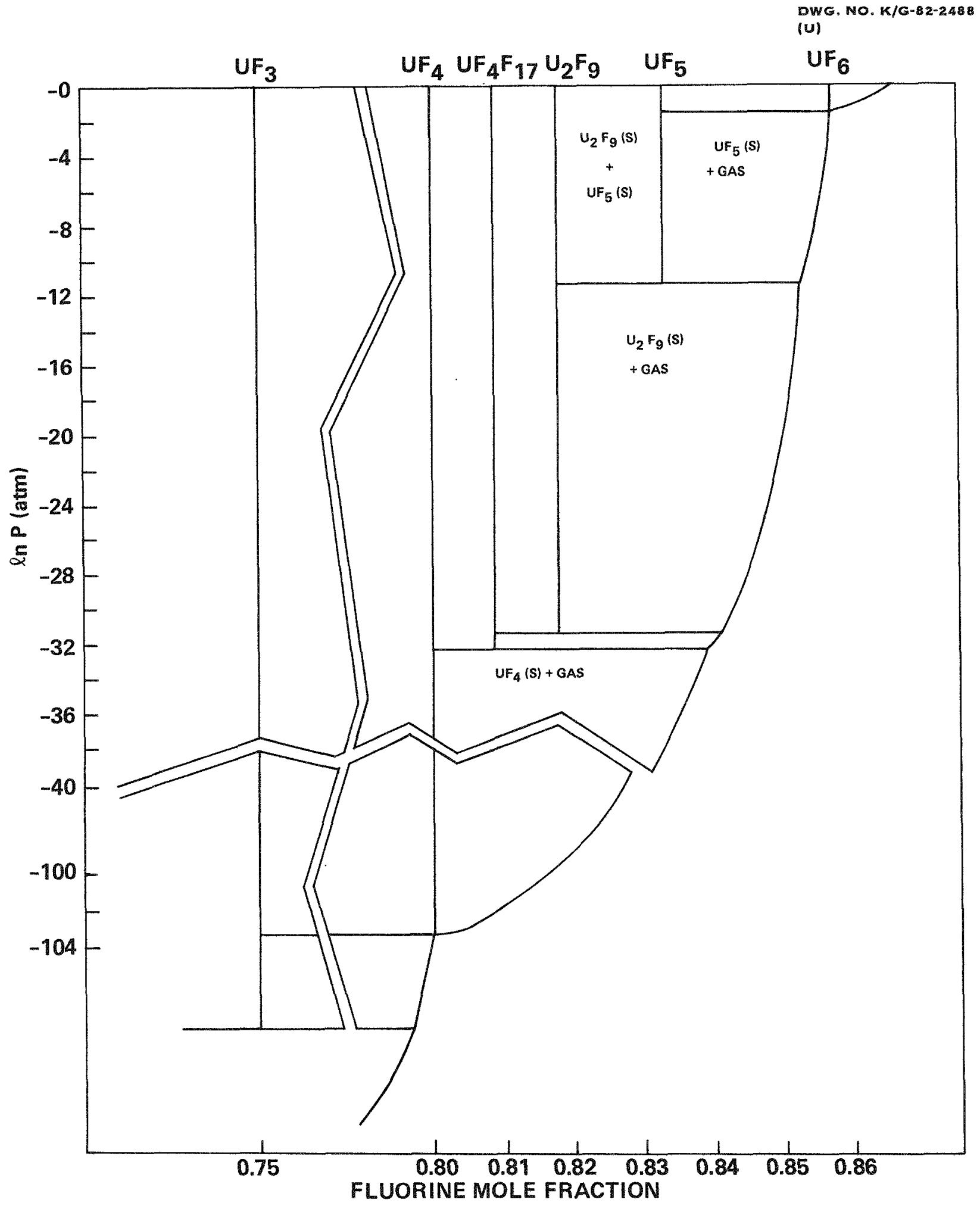

Figure 2

PRESSURE-COMPOSITION RELATIONSHIPS IN THE URANIUM-FLUDRINE SYSTEM 
Table 13

THERMODYNAMIC QUANTITIES FOR URANIUM-FLUORINE COMPOUNDS $(a)$

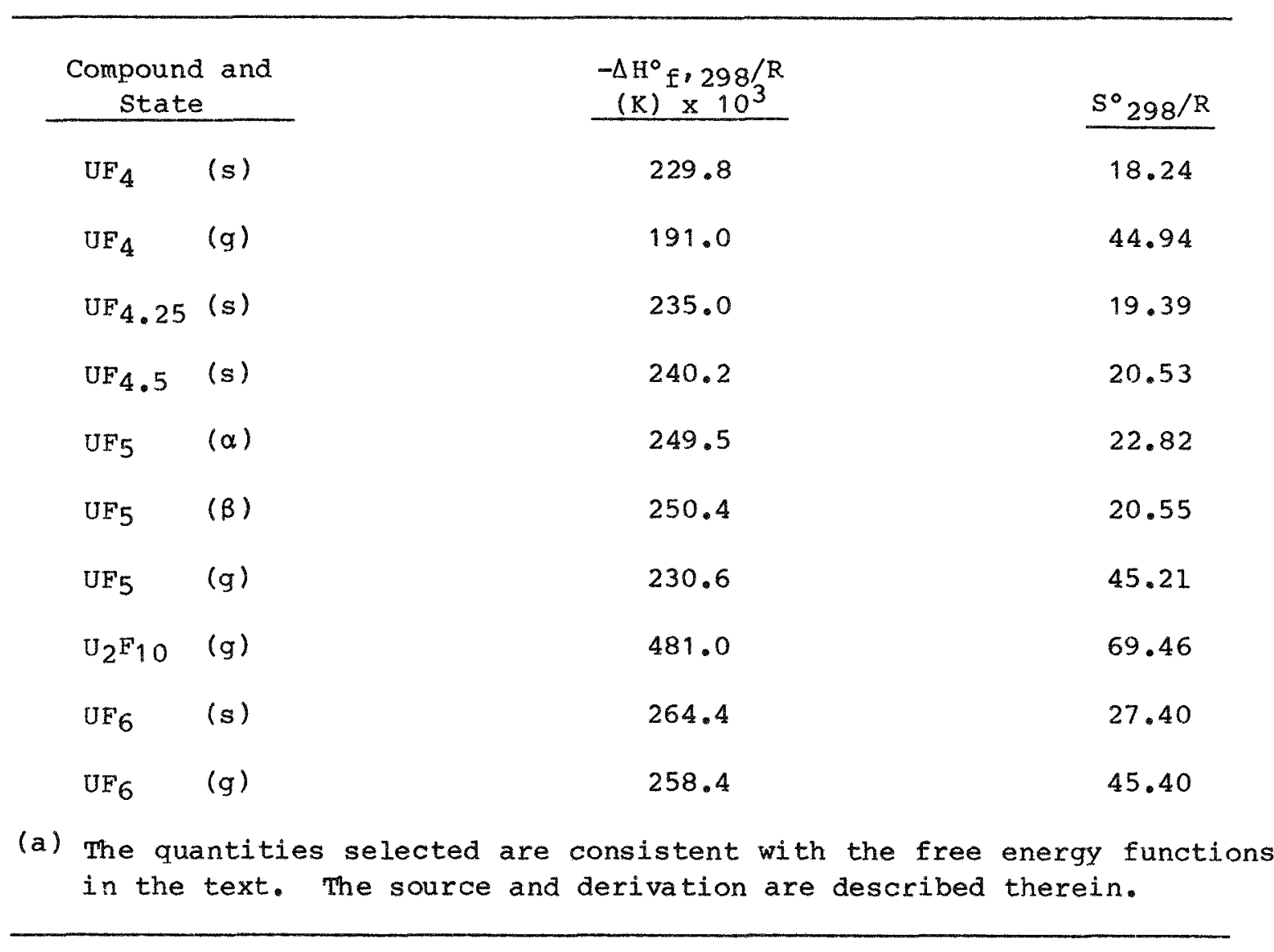


-11.7 one has only two solid phases and no gaseous phase at all. But if the system pressure is lowered, say by easing off on an imaginary piston, when one reaches $a$ ln $P$ of -11.78 a gaseous phase appears, UF 6 primarily. At equilibrium, then one can no longer lower the pressure, that is until all the $\mathrm{UF}_{5}$ is consumed in the reaction

$$
3 \mathrm{UF}_{5}(\mathrm{~s})=\mathrm{U}_{2} \mathrm{~F}_{9}(\mathrm{~s})+\mathrm{UF}_{6}(g) \text {. }
$$

Notice that once the $\mathrm{UF}_{5}$ is consumed the system then moves, on lowering the pressure, into the two-phase region of $U_{2} \mathrm{Fg}$ ( $\mathrm{s}$ ) plus a gas which is largely $\mathrm{UF}_{6}$. One can then lower the pressure until the next three-phase tie-line is reached: $\mathrm{U}_{4} \mathrm{~F}_{1}{ }_{7}-\mathrm{J}_{2} \mathrm{~F}_{9}$-gas.

Notice that this process continues until $\mathrm{UF}_{4}$ (s) is reached as a solid residue. At this point the system will no longer allow the equilibrium pressure to be lowered until all the $\mathrm{UF}_{4}$ is evaporated: the UF 4 evaporates congruently (without change of composition of the condensed phase). The U-F system is unusual, among inorganic systems, in that it has two congruently evaporating intermediate phases, the UF 4 phase and a lso $\mathrm{UF}_{6}$.

Some explanations are necessary concerning the curve giving the composition of the gas phase. Both $\mathrm{UF}_{4}$ and $\mathrm{UF}_{6}$ are congruently vaporizing phases, but it is difficult to see this is true from the drawing. It is not clear, for example, that UF 5 , solid UF 6 , and a gas consisting of mostly $U_{6}$ but lying in composition between $U_{5}$ and UF, are all three at equilibrium. Nor is it clear that a similar situation exists near $\mathrm{UF}_{4}$. Both problems arise because the compositions of the intermediate gas phases lie so close to the solid compounds. The curvature of the line giving the composition of the gas phase may be somewhat exaggerated. In any case, the direction from the UE 6 -gas-UF 5 equilibria is monotonously toward UF 4 as the pressure decreases. Pressures relevant to the diagram are tabulated in Table 14. 
Table 14

EQUILIBRIUM PRESSURES OVER SOLID PHASES IN THE U-F SYSTEM AT $298 \mathrm{~K}$

\begin{tabular}{|c|c|c|}
\hline Equilibria & $\begin{array}{c}\text { Pressure } \\
(\mathrm{atm})\end{array}$ & $\ln \mathrm{P}$ \\
\hline $\mathrm{UF}_{6}(\mathrm{~g})$ over UF 6 (s) & 0.15 & -1.90 \\
\hline $\mathrm{UF}_{6}(\mathrm{~g})$ over $\mathrm{UF}_{5}(\mathrm{~s}), \mathrm{U}_{2} \mathrm{~F}_{9}(\mathrm{~s})$ & $7.7 \times 10^{-6}$ & $-11 \cdot 78$ \\
\hline$F_{2}(g)$ over $\operatorname{UF}_{5}(s), \mathrm{UF}_{6}(\mathrm{~s})$ & $8 \times 10^{-44}$ & -99.23 \\
\hline$U_{5}(g)$ over UF5 $(s)$ & $3.1 \times 10^{-17}$ & -38.00 \\
\hline$U_{2} F_{10}(g)$ over $U_{F}(s)$ & $6.3 \times 10^{-16}$ & -35.01 \\
\hline $\mathrm{UF}_{6}(g)$ over $\mathrm{U}_{2} \mathrm{~F}_{9}(\mathrm{~s}), \mathrm{U}_{4} \mathrm{~F}_{17}(\mathrm{~s})$ & $1.8 \times 10^{-14}$ & -31.62 \\
\hline $\mathrm{UF}_{6}(\mathrm{~g})$ over $\mathrm{U}_{4} \mathrm{~F}_{17}(\mathrm{~s}), \mathrm{UF}_{4}(\mathrm{~s})$ & $8.2 \times 10^{-15}$ & -32.44 \\
\hline $\mathrm{UF}_{4}(g)$ over $\mathrm{UF}_{4}(\mathrm{~s})$ & $1.4 \times 10^{-45}$ & -103.3 \\
\hline $\mathrm{U}(\mathrm{g})$ over U (s) & $4.5 \times 10^{-86}$ & -196.5 \\
\hline
\end{tabular}




\section{BIBL IOGRAPHY}

1. Parker, V. B., The Thermochemical Properties of the Uranium Halogen Containing Compounds, National Bureau of Standards, NBSIR 80-2029, (July 1981).

2. Hultgren, R., Orr, R. L., Anderson, P. D., and Kelley, K. K., Selected Values of Thermodynamic Properties of Metals and Alloys, John Wiley \& Sons, Inc., New York, p. 299 (1963).

3. Stull, D. R., and sinke, G. C., Thermodynamic Properties of the Elements, Am Chem Soc, Washington, D. C., p. 87 (1956).

4. Brickwedde, F. G., Hoge, W. J., and Scott, R. B., "The Low Temperature Heat Capacities, Enthalpies, and Entropies of $\mathrm{UF}_{4}$ and $\mathrm{UF}_{6}$," J Chem Phys, 16 (5), pp. 429-36 (1948).

5. Weinstock, B., Weaver, E. E., and Malm, J. G., "Vapor Pressures of $\mathrm{NpF}_{6}$ and $\mathrm{PuF}_{6}$ : Thermodynamic Calculations with $\mathrm{UF}_{6}, \mathrm{NpF}_{6}$, and $\mathrm{PuF}_{6}, " \mathrm{~J}$ Inorg Nucl Chem, 11, pp. 104-14 (1959).

6. Glauber, R., and Schomaker, V., "The Theory of Electron Diffraction," Phys Rev, 89, pp. 667-71 (1953).

7. Burns, J. H., Osborne, D. W., and Westrum, E. F., Jr., "Heat Capacity of $\mathrm{UF}_{4}$ from 1.3 to $20^{\circ} \mathrm{K}$ and the Thermodynamic Functions to $300^{\circ} \mathrm{K}$. Calorimeter for the Range 0.8 to $20^{\circ} \mathrm{K}$, " I Chem Phys, 33 , pp. 384-94 (1960).

8. Dworkin, A. S., "Enthalpy of Uranium Tetrafluoride from 198-1400\% . Enthalpy and Entropy of Fusion," J Inorg Nucl Chem, 34, pp. 135-38 (1972).

9. King, E. G., and Christensen, A. V., High Temperature Heat Content of Uranium Tetrafluoride, U.S. Bureau of Mines Report of Investigation 5709 (1961).

10. Leitnaker, J. M., Vapor Pressure Measurements on UF 4 : An Analysis, Union Carbide Corporation, Nuclear Division, Oak Ridge Gaseous Diffusion Plant, Oak Ridge, Tennessee, (K/ET-604), May 27, 1981, UNCLASSIFIED.

11. Lau, K. H., and Hildenbrand, D. L., "Thermochemical Properties of the Gaseous Lower Valent Fluorides of Uranium," To Be Rublished.

12. Lohr, H. R., Osborne, D. W., and Westrum, E. J., Jr., "Thermodynamic Properties of Thorium Tetrafluoride from 5 to $300 \circ \mathrm{K}$ and the Magnetic Entropy of Uranium Tetrafluoride," J Am Chern Soc, 76, pp. 3837-39 (1954). 
13. Katz, J. J., and Rabinowitch, E., The Chemistry of Uranium, Part I. The Element, Its Binary and Related Compounds, McGraw-Hill Book Co., Inc., New York, p. 389 (1951).

14. Agron, P. A., The Thermodynamics of Intermediate Uranium Fluorides from Measurements of the Disproportionation Pressures, U.S. Atomic Energy Commission AECD-1878, January 16, 1948, JNCLASSIFIED.

15. O'Hare, P. A. G., Malm, J. G., and Eller, P. G., "Thermochemistry of Uranium Compounds, XII. Standard Enthalpies of Formation of the $\alpha$ and $\beta$ Modified Functions of Uranium Pentafluoride, The Enthalpy of the $\alpha$ to $\beta$ Transition at $298.15 \mathrm{~K}$, "To Be Published.

16. Jones, L. H., and Ekberg, S., "Potential Constants and Structure of the UF 5 Monomer," J Chem Phys, 67, pp. 2591-95 (1977).

17. Krohn, B. J., Person, W. B., and Overend, J., "The Predicted Infrared Spectrum and the Structure of the Isolated UF 5 Molecules," J Chem Phys, 65, pp. 969-76 (1976).

18. Wolf, A. S., Posey, J. C., and Rapp, K. E., " $\alpha$ Uranium Pentafluoride I. Characterization," Inorg Chem, 4 (5), pp. 751-54 (1965).

19. Kleinschmidt, P. D., and Hildenbrand, D. L., "Thermodynamics and Dimerization of Gaseous $\mathrm{UF}_{5}, " \mathrm{~J}$ Chem Phys, 71 (1), pp. 196-201 (1979).

20. Leitnaker, J. M., "Re-Interpretation of the Vapor Pressure Measurements Over UF 5 " High Ternp Sci, 12, pp. 189-96 (1980).

21. Gotkis, I. S., Gusarov, A. V., Pervov, V. S., and Burskii, V. D., "Mass Spectrometric Study of the Thermodynamics of Evaporation and the Mechanism of Formation of Molybdenum Pentafluoride," Koord Khim, 4. p. 720-24 (1978).

22. Gusarov, A. V., Perov, V. S., Gotkis, I. S., Kluev, L. I., and Burskii, V. D., "Some Thermodynamic properties of Tungsten PentaEluoride," Dok1 Akad Nauk SSSR 216 (6), pp. 1296-99 (1974).

23. Johnson, G. K., "The Enthalpy of Formation of Uranium Hexafluoride," J Chem Thermodynamics, 11, pp. 483-90 (1979).

24. Johnson, G. K., and O'Hare, P. A. G., "Thermochemistry of Uranium Compounds XI. Standard Enthalpy of Formation of $\mathrm{UO}_{3}, " \mathrm{~J}$ Chem Thermodynamics, 10, pp. 577-80 (1978).

25. Johnson, G. K., Unpublished Results. 


\section{APPENDIX}

Thermodynamic symbols and usage in this report conforms to most present day usage. Some explanations may aid the casual reader.

The heat capacity at constant pressure is $c_{p}$, the heat required to raise a gram-mole of material one degree. More rigidly it is defined as

$$
C_{P}=\left(\frac{\partial H}{\partial T}\right)_{P}
$$

where $T$ is the absolute temperature in kelvin.

Enthalpy, sometimes referred to as "heat content," is H. Rigidly, it is defined for a substance as

$$
\mathrm{H}=\mathrm{E}+\mathrm{PV}
$$

where $E$ is the internal energy, $P$ is the pressure on the system and $V$ is the volume of the system. It is customary to refer only to changes in enthapy, since absolute values of enthalpy cannot be measured. Enthalpy of formation, for example, is customarily given at a specific reference temperature, indicated by a subscripted value of temperature. The usual reference temperature is $298.15 \mathrm{~K}$, and the decimal point with the two following digits are there only by implication. One usually also indicates that enthalpy values apply under conditions agreed on customarily with respect to pressure and form of material by use of a superscript degree sign. An enthalpy of formation would thus appear as $\Delta \mathrm{H}^{\circ} 298^{\circ}, \mathrm{f}^{\circ}$

Entropy has a more subtle meaning, which sometimes seems mysterious. The symbol, s, can also be subscripted and superscripted as can enthalpy. The absolute value of entropy can be taken for a material as

$$
\mathrm{s}_{\mathrm{T}}^{\circ}=\int_{0}^{\mathrm{T}} \frac{\mathrm{C}_{\mathrm{p}} \mathrm{dT}}{\mathrm{T}}
$$

if no phase changes occur. The entropy change at a phase transformation (e.g., melting) is $\Delta H / T$ at constant pressure.

For any process, the change in Gibbs free energy, G, is given by

$$
\Delta \mathrm{G}=\Delta \mathrm{H}-\mathrm{T} \Delta \mathrm{S}
$$

Like enthalpy and entropy, the Gibbs free energy can be subscripted by temperature and superscripted for "standard conditions."

The gas constant, $R$, has been used in this document to obviate the need for choosing appropriate units for entropy, heat capacity, and Gibbs free energy. Each of these quantities has a unit of quantity (e.g., mole), a unit of temperature (e.g., kelvin), and a unit of heat (e.g., calorie). Since the gas constant has the same units, division of $\mathrm{Cp}$ or 
$S$ by $R$ makes the quantity dimensionless. If $H$ or $G$ is divided by $R$, the resulting unit is temperature--and, in this report, is always kelvin.

In some cases in this report values of quantities are given in the units chosen by other authors. Most of these will be self evident as, for example, joules-mole $e^{-1}$. The conversion via the latest internationaly accepted standards will also be self evident. An exception may be the entropy unit, abbreviated e.u. The units of e.u. are customarily calories-mole -1 degree $e^{-1}$. 
Distribution

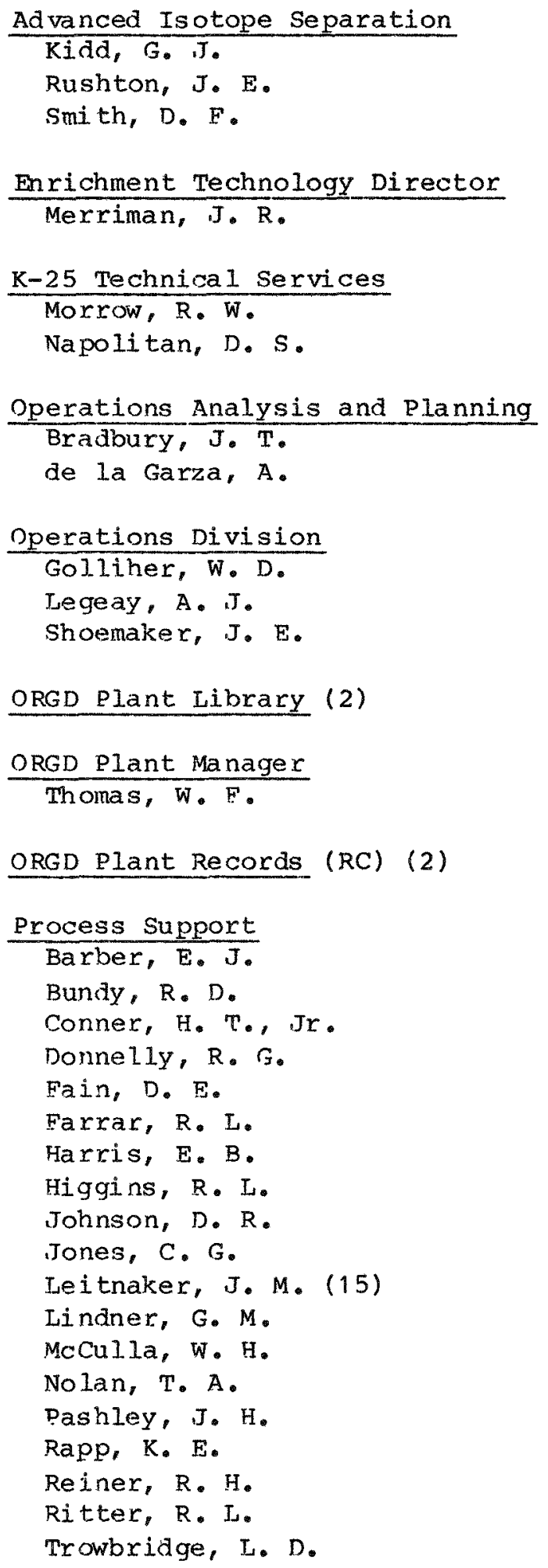

ORGD Plant Manager

Thomas, W. F.

ORGD Plant Records

(RC) (2)

Process Support

Barber, E.J.

Bundy, R. D.

Conner, H. T., Jr.

Donnelly, R. G.

Fain, D. E.

Farrar, R. I.

Harris, E. B.

Higgins, $R$. I.

Johnson, D. R.

Tones, C. G.

Leitnaker, J. M. (15)

Lindner, G. M. MCCulla, W. H. Nolan, T. A.

Pashley, J. H. Rapp, K. E.

Reiner, $\mathrm{R}$. H. Ritter, R. I. Trowbridge, I. D.

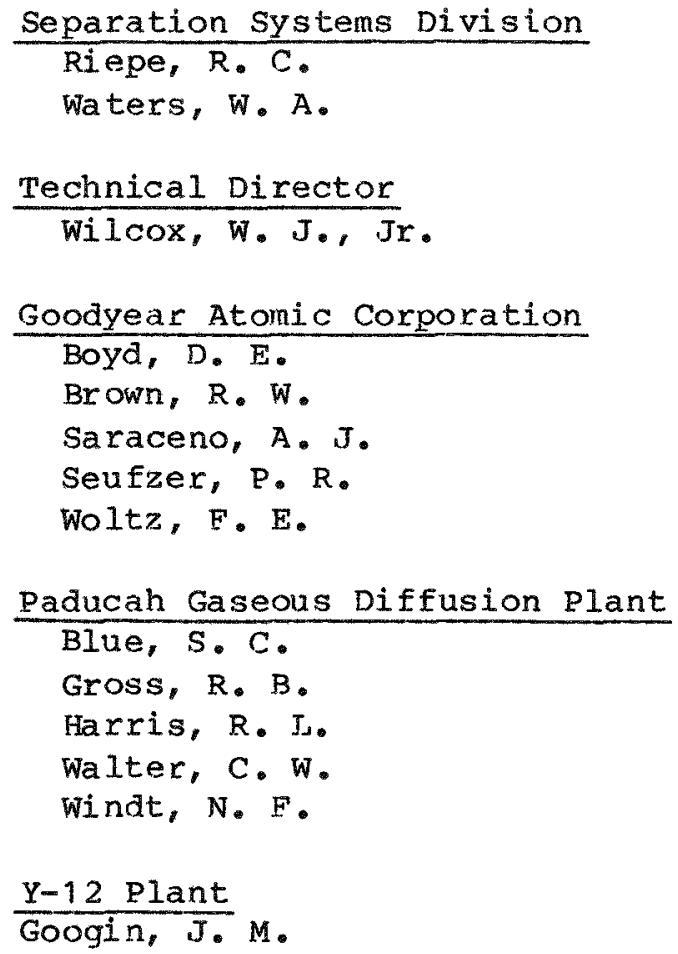

